\title{
3'HS1 CTCF binding site in human $\beta$-globin locus regulates fetal hemoglobin expression
}

Pamela Himadewi ${ }^{1,8}$, Xue Qing David Wang ${ }^{1,8}$, Fan Feng ${ }^{3,8}$, Haley Gore ${ }^{1}$, Yushuai Liu', Lei Yu², Jie Liu ${ }^{3}$, Ryo Kurita ${ }^{4}$, Yukio Nakamura ${ }^{5,6}$, Gerd Pfeifer ${ }^{1}$, and Xiaotian Zhang ${ }^{1,7}$.

1. Center for Epigenetics, Van Andel Research Institute, Grand Rapids, MI, USA

2. Cell and Development Biology, University of Michigan, Ann Arbor, MI, USA

3. Department of Computational Biology, University of Michigan, Ann Arbor, MI, USA

4. Department of Research and Development, Central Blood Institute, Japanese Red Cross Society, Tokyo,Japan.

5. Cell Engineering Division, RIKEN BioResource Research Center, Tsukuba, Japan

6. Faculty of Medicine, University of Tsukuba, Tsukuba, Japan

7. Current Address: Department of Pathology, University of Michigan

8. These authors contributed equally to the work

Correspondence should be directed to:

Xiaotian Zhang

xiaozhan@umich.edu 


\section{Summary}

Mutations in the adult $\beta$-globin gene can lead to a variety of hemoglobinopathies, including sickle cell disease and $\beta$-thalassemia. An increase in fetal hemoglobin expression throughout adulthood, a condition named Hereditary Persistence of Fetal Hemoglobin (HPFH), has been found to ameliorate hemoglobinopathies. Deletional HPFH occurs through the excision of a significant portion of the 3 ' end of the $\beta$-globin locus, including a CTCF binding site termed 3'HS1. Here, we show that the deletion of this CTCF site alone induces fetal hemoglobin expression in both adult CD34+ hematopoietic stem and progenitor cells and HUDEP-2 erythroid progenitor cells. This induction is driven by the ectopic access of a previously postulated distal enhancer located in the OR52A1 gene downstream of the locus, which can also be insulated by the inversion of the 3'HS1 CTCF site. This suggests that genetic editing of this binding site can have therapeutic implications to treat hemoglobinopathies. 


\section{Introduction}

The human $\beta$-globin locus consists of five globin genes embedded in the olfactory receptor cluster. During early development, these globin genes undergo gene switching from embryonic $\varepsilon$-globin $(H B E)$ to fetal $\gamma$-globin (HBG1/2) and finally to adult $\beta$-globin $(H B B)$. Inherited mutations in the $H B B$ gene lead to dysfunction of the adult $\beta$-globin protein, causing hemoglobinopathies(Bauer et al., 2012). The symptoms of these disorders, including sickle cell disease and $\beta$-thalassemia, can be alleviated by persistent expression of fetal hemoglobin (HPFH) throughout adulthood, which compensates for the mutant adult $\beta$-globin(Bank, 2006; Hassell, 2010). As such, multiple genome editing strategies have been proposed to mimic HPFH as a treatment for hemoglobinopathies(Bauer et al., 2012; Breda et al., 2016; Sankaran et al., 2008; Sankaran et al., 2011; Sankaran et al., 2009; Traxler et al., 2016; Xu et al., 2011; Ye et al., 2016; Zeng et al., 2020). Two types of HPFH have been identified based on patient genetics. First is the non-deletional HPFH caused by point mutations in the BCL11A binding site at the HBG1/2 promoters, and disruption of this transcriptional repressor binding leads to the activation of these genes(Forget, 1998; Liu et al., 2018; Martyn et al., 2018; Traxler et al., 2016). Second is the deletional HPFH that consists of the excision of a large genomic region within the $\beta$-globin locus, frequently including $H B B$ and $H B D$ (Forget, 1998; Ye et al., 2016). These deletions can vary in length and it remains unclear as to how they lead to the expression of fetal globin in adulthood(Ye et al., 2016).

\section{Results}

The human $\beta$-globin gene locus is flanked by five CTCF binding sites (CBSs), which form the anchors for six chromosomal loops(Huang et al., 2017). Two convergent CBSs, designated as 3'HS1 and HS5, are located at the borders of the globin gene cluster. These two CBSs are nested between a downstream CBS (referred to as 3'-OR52A5-CBS) and two closely spaced upstream CBSs (referred together as 5'-OR51B5-CBSs). The HPFH deletions frequently cover the 3'HS1 CTCF binding site (Figure 1A). Therefore, we hypothesized that 3'HS1 may play a role in regulating $\beta$-globin cluster gene expression. To explore this, we first deleted the 3'HS1 using CRISPR/Cas9 genome editing technology in K562 myelogenous leukemia cells, which express high levels of hemoglobin (Figure S1A). At the same time, we also deleted HS5 as a control in K562 cells. We observed that deletion of the HS5 CTCF site resulted in the upregulation of the 3' genes including $H B B$ and HBG1/2. Interestingly, the disruption of 3'HS1 CBS lead solely to the upregulation of $H B G 1 / 2$ (Figure S1B, C). These results show that altering the CTCF binding profile across the locus can significantly change the expression of the $\beta$ globin genes.

As HPFH deletions frequently cover the 3'HS1 CBS, we hypothesized that this site may contribute to the regulation of HBG1/2. To investigate further, we utilized the HUDEP-2 erythroid progenitor cell model, which predominantly express adult $\beta$-globin. We performed CRISPR/Cas9 editing to delete and invert the orientation of the 3'HS1 CBS to observe their respective impact on the expression of $H B G 1 / 2$ (Figure 1B). In bulk edited cells, we found that HS5 deletion did not alter globin gene expression significantly, yet 3'HS1 disruption did increase Y globin gene expression as observed in K562 cells with low deletion percentage (Figure S1D, 
E) with low editing effiency. Subsequently, we generated two 3'HS1 CBS deletion clones (referred to as B6 and D3) and two 3'HS1 inversion clones (A2 and G3), whose genomic sequences were verified by Sanger sequencing and CTCF binding evaluated by CUT\&RUN (Figure 1D, E, Figure S1F). To elucidate whether the genetic editing at 3'HS1 caused changes to gene expression, we differentiated the HUDEP-2 clones to activate $\beta$-globin expression.

We performed $\mathrm{Hi}-\mathrm{C}$ and capture $\mathrm{Hi}-\mathrm{C}$ to examine the changes to $3 \mathrm{D}$ chromatin organization at the $\beta$-globin locus following alterations to the CBSs (Figure S2A, Figure 1C-E). In situ $\mathrm{HiC}$ data was generated with high resolution at $5 \mathrm{~kb}$. A total of 15207 to 16529 loop could be detected in the HUDEP-2 clones used for in situ HiC using Mustache (Figure S2A) (Roayaei Ardakany et al., 2020). The CTCF bound around the $\beta$-globin locus form 4 chromosomal loops and separate the cluster into 3 distinct domains (Figure 1A, C. Figure S2B). Of notice, we could detect the enhancer to target gene interaction between the LCR and the HBB gene (Figure $\mathrm{S} 2 \mathrm{~B})$. We also tested the copy number variance (CNV) in the 3 particular HUDEP-2 clones, we could verify all clones have chromosome number 49-50, $\mathrm{XY}$, which is of normal range in unmodified HUDEP-2 cells (Figure S2C) (Moir-Meyer et al., 2018; Vinjamur and Bauer, 2018). Next, we tested if the chromosomal loops were altered by the 3'HS1 editing. We firstly applied the HiCCUPS method to call the significant chromosomal loops in the $\beta$ globin locus, four loops were identified with q value less 0.1 (Figure1C,F). Of the convergent CTCF interactions, 3'HS1 to 5'-OR51B5-CBSs was not called as loop with q value over 0.25. One loop was called between the two forward CTCF CBSs - 3'HS1 and 3'-OR52A5 CBS (Figure 1D,F). In the 3'HS1 deletion clone, the loss of CTCF at 3'HS1 resulted in the total loss of loops between 3'HS1 and HS5 as well as loops between 3'HS1 and 5'-OR51B5-CBSs (not called as loop). Concomitantly, a strong increase in the interaction between HS5 and 3'-OR51A5-CBS was observed (Figure $1 \mathrm{D}, \mathrm{F}$, Figure S2A). This reveals how the loss of a CTCF anchor drastically alters the 3D chromatin organization in the $\beta$-globin locus. The inversion of the 3'HS1 CTCF caused a significant increase in the interaction between 3'HS1 and 3'-OR52A5 CBS. Both 3'HS1 upstream interactions with HS5 and 5'-OR51B5-CBSs were as well, decreased (Figure 1E, F, Figure S2A). This revealed that the inversion of 3'HS1 CTCF drove the formation of chromosomal loops between the convergent CBSs, which may lead to stronger insulation of regulatory elements.

Next, we evaluated the expression of the $\beta$-globin genes and found the HBG1/2 and $H B E$ genes upregulated 2.5 to 8 -fold in the $\triangle 3^{\prime} H S 1$ clones (Figure $1 \mathrm{G}, \mathrm{H}$ ). In contrast, the inversion of 3'HS1 resulted in a $>50 \%$ reduction of $H B E$ and near-complete depletion of $H B G 1 / 2$ (Figure $1 \mathrm{H}$ ). Most notably, the increase in HBG1/2 upon deletion of the 3'HS1 CTCF site leads to a significant increase in fetal hemoglobin $\mathrm{HbF}$ (Figure 1I). Consequently, we evaluated the clones for $\mathrm{HbF}+$ cells by flow cytometry. Consistent with transcription level, we observed an increase in $\mathrm{HbF}+$ cells from $4.3 \%$ in the Cas9 control clone to $37.8 \%$ and $53.1 \%$ in $\Delta 3{ }^{\prime} \mathrm{HS} 1 \mathrm{~B} 6$ and D3 clones, respectively (Figure 1J). Meanwhile, inversion of 3'HS1 resulted in a decrease of $\mathrm{HbF}+$ cells to below $1 \%$. In contrast, deletion of the upstream HS5 CBS did not induce nor abrogate the quantity of $\mathrm{HbF}+$ cells (Figure $1 \mathrm{lJ}$. All these clones are well differentiated at the same stage when $\mathrm{HbF}$ is measured by flow-cytometry (Figure S3).

We then performed ATAC-seq and H3K27ac ChIP-seq in the $\triangle 3^{\prime} H S 1$ and 3 'HS1 inversion clones to examine the regulatory landscape of the $\beta$-globin gene cluster. Following 
3'HS1 CBS deletion, we observed significant open chromatin at the HBG1/2, BGLT2, and HBBP1 genes (Figure S4A). There was also a significant increase in activating H3K27ac in the HBG2 gene body, and the region with significant peak increase is not associated with BCL11A binding at the HBG1/2 promoter region (Figure S4A).

To determine if other regulatory pathways, such as the transcriptional repressor BCL11A, are involved in the upregulation of $\mathrm{y}$ globin expression in $\triangle 3^{\prime} H S 1$ and 3'HS1 inversion clones, we performed RNA-seq to identify differentially expressed genes in these clones. We found 161 upregulated and 153 downregulated genes in the $\triangle 3^{\prime} H S 1$ clones with $H B G 1 / 2$ genes being the most significantly upregulated as well as $\beta$-globin cluster genes $H B E 1, H B B P$, and $B G L T 3$ (Figure 2A, C). In the 3'HS1 inversion clones, we identified only three upregulated genes and 51 downregulated genes (Figure 2B). In these clones, we observed downregulation of HBG2 and upregulation of the nearby OR52A5 gene; however, we did not observe any change in the expression of known $\mathrm{Y}$ globin regulators (BCL11A, ZBTB7A (LRF), ELF2AK1 (HRI), ATF4, ZNF410, and NFIX) (Figure 2B, D. Supplemental Table S1-2) (Grevet et al., 2018; Masuda et al., 2016). We further verified BCL11A protein level by immunoblotting and observed no significant reduction in $\triangle 3^{\prime} H S 1$ clones (Figure 2E). Taken together, we concluded that BCL11A does not contribute to the induction of HbF in the edited HUDEP-2 cells. To further elucidate the role of BCL11A in the regulation of $H B G 1 / 2$, we performed targeted disruption of a known BCL11A gene enhancer in both WT and $\triangle 3^{\prime} H S 1$ HUDEP-2 clones (Figure S4B)(Bauer et al., 2013). This mutation resulted in significantly lower BCL11A expression and we observed further increase of $H B G 1 / 2$ expression level and $\mathrm{HbF}+$ cells (Figure 2G, Figure S4C-F). Pomalidomide was found to boost the level of $\mathrm{HbF}$ in adult erythroblasts by de-stabilizing the BCL11A protein in cells(Grevet et al., 2018). Therefore, we treated HUDEP-2 3'HS1 deletion clones with pomalidomide and observed a significant reduction in BCL11A protein. This led to further increase in expression of fetal globin (Figure S5A-D). These results show that genetic editing of the regulatory cis-element (3'HS1 CBS) synergizes with depletion of the transcriptional repressor BCL11A. This further indicates the $\mathrm{Y}$ globin activation in 3'HS1 deletion HUDEP-2 cells was not driven by the BCL11A associated pathways. The double disruption of BCL11A and 3'HS1 also lead to similar level of $Y$ globin activation as the disruption of BCL11A alone (Figure 2F). This data suggests that 3'HS1 regulated $Y$ globin repression might be hypostatic to the BCL11A mediated $\mathrm{y}$ globin repression.

Deletional HPFH has been proposed to be the result of distal enhancer juxtaposition in the region downstream of 3'HS1, and several HPFH enhancers have been identified(Forget, 1998). The reduction of HbF in the 3'HS1 inversion HUDEP-2 clones suggests that potential enhancers may be located between 3'HS1 and 3'-OR52A5-CBS. These enhancers may be insulated by the loop formed between 3'HS1 to 3'-OR52A5-CBS in the inversion clones. With no significant change in chromatin interaction observed between the LCR and HBG1/2 genes (Figure S2C, D), it suggests that the HBG1/2 expression increase is controlled by a cis-element other than the LCR. We then analyzed the ATAC-seq, GATA1 ChIP-seq data together to search for potential cis-regulatory elements. We found the OR52A1 region bound by the GATA1 transcriptional activator in the erythroid lineages(Corces et al., 2016; Feingold and Forget; Liu et al., 2018) (Figure 3A). Importantly, the mapping of a previously described HPFH1 enhancer encompassed both OR52A1 gene and GATA1 binding site(Feingold and Forget, 1989). We 
proceed to delete the GATA1 binding site within the HPFH1 enhancer site and the entire HPFH1 enhancer marked by ATAC-seq in $\triangle 3^{\prime} H S 1$ clones (Figure $3 B$ ). We found that both deletions reduced the $H B G 1 / 2$ expression and $\mathrm{HbF}+$ cell percentage in these cells, suggesting that the HPFH1 enhancer contributes to the activation of HBG1/2 (Figure 3C-E). We further tested the if there were direct interactions between $H B G 1 / 2$ and HPFH after the deletion of 3'HS1 by virtual $4 \mathrm{C}(\mathrm{V} 4 \mathrm{C})$ in our HiC dataset. We observed increased v4C signal in HBG2 promoter region of $\triangle 3^{\prime} \mathrm{HS} 1$ cells compared with WT and 3'HS1 inversion clones when HPFH-1 region acts as viewpoint (Figure $S 7$ ). Vice versa, we also observed increased $\mathrm{V} 4 \mathrm{C}$ signal in $\mathrm{HPFH}-1$ region of $\triangle 3$ 'HS1 cells compared with WT and 3'HS1 inversion clones when HBG2 promoter region act viewpoint (Figure S6). These data suggest the deletion of 3'HS1 might induced more frequent interaction between HPFH-1 and HBG2 promoter regions.

Previously, mouse and human $\beta$-globin locus and its surrounding regions has been shown to be evolutionally conserved (Bulger et al., 2003). More interestingly, previous report showed that the disruption of 3'HS1 site in mouse did not result in any change in the $\beta$-like globin gene expression(Bender et al., 2006). We hypothesized that the alteration of HPFH enhancer sequence might contribute to the different outcome of 3'HS1 deletion in mouse and human. Therefore, we firstly checked the evolutionary conservation of OR52A1 in mammals and found mouse and rat homolog of human OR52A1- Olfr68 bears two single nucleotide substitutions right at the core binding site of GATA1 (Figure 3F). When we further checked the GATA1 ChIP-seq in mouse erythroid cells, we also found the absence of binding in the OR52A1's homolog Olfr68 and its surrounding region (Figure 3G). This data suggesting the mouse olfactory receptor region 3' to $\beta$-globin genes no long bears GATA1 binding sites and enhancer activity. Overall, the loss of GATA1 binding in mouse clearly explains the difference between mouse and human on the effect of 3'HS1 deletion on globin gene expression.

Previously, it is proposed that the juxtaposition of HPFH enhancer result in the activation of $y$ globin. We wonder if the chromosomal distance between HPFH enhancer and globin genes also contributes to the regulation of globin gene expression. We use paired guide RNA to delete a 48kb region between HPFH enhancer and 3'HS1, to access the effect of distance between enhancer and target genes in the presence of chromosomal insulators (Figure S6A). We have obtained a heterozygous clone bearing this $48 \mathrm{~kb}$ deletion (Figure S6A). We found moving the HPFH enhancer to the proximity of globin locus mildly increase the HBG1/2 gene expression by 2 fold (Figure S6B,C). Overall, the data suggests that both chromosomal distance and insulator contribute to the low expression of $H B G 1 / 2$, but chromosomal insulators are dominat to insulate HPFH enhancer to access the globin genes.

To assess the therapeutic potential of 3'HS1 deletion in primary HSPCs, we performed the 3'HS1 and HS5 CBS deletions in adult mobilized peripheral blood CD34+ HSPC from 3 different donors (Figure 4A). We achieved high deletion percentage of both CBSs in these primary cells (Figure $4 \mathrm{~B}$ ). Upon differentiation, we observed a robust increase in $\mathrm{HbF}+$ cells across all three donors with 3'HS1 deletion but not with HS5 deletion (Figure 4C, D). The normal erythroid differentiation was not affected by either CBS deletion (Figure S7A-B). While the disruption of the 3'HS1 CBS in primary patient cells did not yield as great of an effect on $\mathrm{HbF}+$ cells as in HUDEP-2 cells, the results do support the involvement of a downstream cisacting regulatory element on the HBG1/2 genes. 
Finally, based on our data, we propose a model where the 3'HS1 CBS modulates the HPFH enhancer's access to the HBG1/2 genes (Figure 4E).

\section{Discussion}

Here, we show that the deletion of a CTCF binding site - 3'HS1- in the human $\beta$-globin locus can phenocopy HPFH. This condition is driven by alteration of the 3D genomic organization around the $\beta$-globin locus, which allows the long-range interaction of a distal enhancer in the OR52A1 gene to drive the expression of $H B G 1 / 2$. We further show that inversion of 3'HS1 insulates the enhancer element and further suppresses $H B G 1 / 2$. Previously, induced LCR to HBG1/2 interaction showed the importance of high-order chromatin structure in the regulation of globin gene expression(Breda et al., 2016; Deng et al., 2014). However, the role of CTCF protein bound around the gene cluster was not clear. Our study reveals how CTCF binding at this locus modulates the accessibility of the fetal HBG1/2 genes to a downstream enhancer. In the HPFH enhancer scenario, 3'HS1 limits the HPFH-1 enhancer access to $H B G 1 / 2$ by forming the TAD with 5'HS (Figure 4E). When the 3'HS1 CBS is deleted, the HPFH enhancer gains access to HBG1/2 without the hinder of 3'HS1 - HS5 TAD. When the 3'HS1 CBS motif is inverted, the HPFH enhancer is further restricted by the pairing of 3'-OR52A5-CBS to the inverted 3'HS1 CBS, which result in the strong insulated TAD formation between the two CBSs. This insulation leads to the reduced HBG1/2 expression and upregulation of OR52A5 (Figure 4E, Figure 2B).

Furthermore, we have elucidated the function of long speculated HPFH enhancer in the induction of $\mathrm{HbF}$ with our $\triangle 3^{\prime} \mathrm{HS} 1$ cells. However, we suspect other regulatory elements also exist between 3'HS1 and 3'-OR52A5-CBS, since we only get a partial decrease of HBG1/2 expression with HPFH1 enhancer deletion in $\triangle 3^{\prime} H S 1$ cells. This may suggest that other previously identified HPFH enhancers also contribute to HbF induction in the $\Delta 3^{\prime} H S 1$ cells(Feingold and Forget, 1989; Forget, 1998). Indeed, other GATA1 binding sites can be observed between OR52A1 and OR52A5 genes of erythroid progenitor cells. Overall, these observations suggest that GATA1 binding across the locus work collectively to activate HBG1/2 expression with or without direct promoter-enhancer interactions. Interestingly, despite the evolution conservation of OR52A1 gene in mammals, TF binding disrupting substitution occurs at the GATA1 binding site in HPFH enhancer in some mammal species that does not express distinct form of fetal hemoglobin (mouse and rat) (Figure $3 F, G$ ). This evolutionary alteration in the TF binding site suggests HPFH enhancer may also play a role in regulating globin expression in other developmental stages. The consistent binding of GATA1 in high $H B E / H B G$ expressing K562 cells and high HBB expressing HUDEP-2 cells suggests that the potential function of HPFH enhancer may still need the modulation of 3D genomic re-organization.

Despite our data suggests deletion of 3'HS1 is sufficient to induce the y globin activation. Yet, the upregulation does not completely phenocopy the HPFH condition, in which the HbF is expressed at pancellular level. The deletion of 3'HS1 only induces a portion of cells to be F+ cells, with an interesting differentiation block phenotype in a large portion of clones we have selected (Figure 1J). Although HUDEP-2 is known to be heterogenous in clonal level, the F+ cell phenotype of 3'HS1 deleted cells suggests the full HPFH phenotype may require the 
deletion of $H B B$ and $H B D$ genes to erase the strong enhancer-promoter interaction between LCR and $H B B$. Furthermore, our results indicate that the distance between HPFH enhancer and the globin locus could also play a role in regulating $\mathrm{Y}$ globin gene expression. This data hints that the deletion of both 3'HS1 and the flanking region between 3'HS1 and HPFH enhancer may activate the fetal hemoglobin to an even higher level. Larger deletions will result in the reorganization of chromosomal loop interactions as well as the decrease of physical distance from HPFH enhancer to globin locus. The enhancers have to locate at certain range of distance from the target gene promoters to exert the maximal activation effect (Jessica Zuin, 2021). Therefore, a method that can create large deletion that disrupts 3'HS1 and reduces enhancerpromoter distance simultaneously could be a potential gene therapy to effectively activate the $Y$ globin expression in hemoglobinopathies.

\section{Figure Legend}

Figure1. 3'HS1 modulates the hemoglobin gene expression in $\beta$-globin gene cluster. (A). Genome wide $\mathrm{HiC}$ interaction map and regulatory landscape around $\beta$-globin gene cluster in human HUDEP2 cells. ATAC-seq and CTCF track of HUDEP2 cells (Liu et al., 2018) is shown in the lower panel. Black cycle indicates the position of loops previously identified(Huang et al., 2017). Yellow dotted line indicates the 3 sub-TAD domians identified previously(Huang et al., 2017). HPFH1-7 deletion is illustrated and 3'HS1 is marked in blue shade. (B). The scheme of CTCF binding motif orientation engineering in HUDEP-2 cells. (C-E). Capture HiC contact map around $\beta$-globin gene cluster in HUDEP-2 cells of wild type (C), 3'HS1 deletion (D) and 3'HS1 inversion (E). CTCF Cut\&Run tracks of WT (Liu et al., 2018), 3'HS1 deletion and 3'HS1 inversion HUDEP-2 cells are shown on top of corresponding HiC plots. Black circles indicate the chromosomal loop location formed by convergent CBSs in WT HUDEP-2 cells. Dark blue circles indicate the chromosomal loop formed by the same orientation CBSs. (F). The HiCUPPS quantification of loops by $q$ vaule in $\beta$ globin locus. Dotted line annotates $q=0.1$. n.d: not detected by HiCUPPS ( $q$ value $>0.1$ ). (G). The composition of $\beta$-like globin HUDEP-2 cells with 3'HS1 deletion. qPCR measurement of $\beta$-like globin HUDEP-2 in two clones (B6 and D3) of $\triangle$ 3'HS1 HUDEP-2 cells is shown. Mean \pm SD is displayed, $n=3$. (H). Left panel: Relative expression of $H B E, H B G$ (probe measures both HBG1 and HBG2) and HBB in the 3'HS1 deleted HUDEP-2 clone B6. Mean $\pm S D$ is displayed, $n=3$. Right panel: Relative expression of $H B E, H B G$ (probe measures both HBG1 and HBG2) and HBB in the 3'HS1 inverted HUDEP-2 clone $A 2$. Mean $\pm S D$ is displayed, $n=3$. (I). The right panel shows the HPLC for globin composition in Cas9 treated HUDEP-2 control and 3'HS1 deletion clone B6. (J). Flow cytometry plot of HbF in HUDEP-2 cell clones with 3'HS1 deletion (B6 and D3) , 3'HS1 inversion (A2 and G3) and $\triangle \mathrm{HS} 5$ clone.

\section{Figure2. The induction of $\mathrm{HbF}$ in $\triangle 3^{\prime} H S 1$ cells is BCL11A independent.}

(A). Volcano plot of differentially expressed genes in two $\triangle 3^{\prime} H S 1$ clones (B6 and D3) vs two wild-type HUDEP-2 biological duplicates. Differentially expressed globin and olfactory receptor genes are labeled. (B). The volcano plot of differentially expressed genes in two 3'HS1 inversion clones (A2 and G3) vs two wild-type HUDEP-2 biological duplicates. Differential expressed globin and olfactory receptor genes are labeled. (C). Expression level of $\beta$-globin 
genes in $\triangle 3^{\prime} H S 1$ clones, 3'HS1 inversion clones and wild type HUDEP-2 cells (D). Expression level of known fetal hemoglobin repressor genes in $\triangle 3^{\prime} H S 1$ clones, 3'HS1 inversion clones and wild type HUDEP-2 cells (E). Western blot shows the level of BCL11A and ZBTB7A (LRF) in $\triangle$ 3'HS1 clones 3'HS1 inversion clones, $\triangle 3$ 'HS-5 clones and wild type HUDEP-2 cells. (F). The composition of $\beta$-like hemoglobin genes in the WT HDUEP-2 cells with $B C L 11 A+58$ enhancer deleted with CRISPR/Cas9 and $\triangle 3^{\prime} H S 1$ HDUEP-2 cells with $B C L 11 A+58$ enhancer deleted with CRISPR/Cas9.

Figure3. The induction of $\mathrm{HbF}$ in $\triangle 3^{\prime} \mathrm{HS} 1$ cells is modulated by $\mathrm{HPFH}-1$ enhancer.

(A). Upper Panel: IGV view of ATAC-seq in primary human blood cells followed by GATA1 and CTCF ChIP-seq in HUDEP-2 cells around the $\beta$-globin locus. Lower panel: ATAC-seq of CD34+ HSPC, MEP and Erythroblast is shown in the zoomed view for the OR52A1 region. Red shaded area indicates the locus of OR52A1. HPFH 3' beak and $\delta \beta$-thelassemia 3 ' break is annotated(Feingold and Forget, 1989). (B). The experimental scheme of HPFH deletion in the 3'HS1 deletion background. (C). The composition of $\beta$-like globin $\triangle 3$ 'HS1 (clone B6) HUDEP-2 cells with GATA1 binding site and HPFH region deletion. Mean $\pm S D$ is displayed, $n=3$. (D). Relative expression of $H B E, H B G$ (probe measures both $H B G 1$ and $H B G 2$ ) and $H B B$ in the $\triangle 3$ 'HS1 (clone B6) HUDEP-2 cells with GATA1 binding site and HPFH region deletion. Mean $\pm S D$ is displayed, $n=3$. (E). The representative $\mathrm{HbF}$ flow plot of $\Delta 3^{\prime} \mathrm{HS} 1$ (clone B6) HUDEP-2 cells with GATA1 binding site and HPFH region deletion. (F). Evolution conservation of OR52A1 GATA1binding site in vertebrates. GATA1 binding motif is shown in the middle. The site in mouse and rat associated with human GATA1 binding is boxed out. (G). Chromatin landscape of mouse $\beta$-globin gene cluster in mouse erythroid cells MEL and G1-ER4. CTCF, GATA1 and TAL1 ChIP-seq is shown. Orange stripe highlighted the mouse homolog of human OR52A1 - Olfr68.

\section{Figure4. Deletion of 3'HS1 induces HbF in primary adult HSPC.}

(A). The experimental scheme for primary HSPC editing. (B). The deletion of 3'HS1 and HS5 in 3 CD34+ PBMC HSPCs from three individual adult donors. (C). The HbF+ cell percentage at day21 in 3 HSPCs from three individual adult donors after 3'HS1 and HS5 deletion. $\mathrm{p}$ value is calculated by one-tailed paired t-test. n.s: not significant, $\mathrm{p}=0.3659$ in HS5 deletion vs Cas9 by one-tailed paired t-test. (D). The reprehensive flow plot for $\mathrm{HbF}+$ cells at day 21 in 3'HS1 deleted and HS5 deleted PBMC HSPC. The data is from donor \#1. (E). The model of fetal hemoglobin regulation through 3'HS1.

\section{Methods and Material}

Key resources table

\begin{tabular}{|l|l|l|}
\hline REAGENT or RESOURCE & SOURCE & IDENTIFIER \\
\hline Antibodies & Abcam & AB70303 \\
\hline CTCF & Abcam & AB191401 \\
\hline BCL11A & Proteintech & $20536-1-A P$ \\
\hline$\beta$-actin
\end{tabular}




\begin{tabular}{|c|c|c|}
\hline$\beta$-globin & $\begin{array}{l}\text { Santa Cruz } \\
\text { Biotechnology }\end{array}$ & SC-21757 \\
\hline V-globin & $\begin{array}{l}\text { Santa Cruz } \\
\text { Biotechnology }\end{array}$ & SC-21756 \\
\hline ZBTB7A & R\&D systems & MAB3496 \\
\hline Human HbF-FITC & Miltenyl Biotec & $130-108-241$ \\
\hline Human CD71-PE & BioLegend & 334105 \\
\hline Human CD235a-APC & BD Biosciences & 561775 \\
\hline $\begin{array}{l}\text { Starbright B700-conjugated } \\
\text { goat } \alpha \text {-rabbit lgG }\end{array}$ & Bio-Rad & 12004161 \\
\hline $\begin{array}{l}\text { DyLight } 800 \text { goat } \alpha \text {-mouse } \\
\text { lgG }\end{array}$ & Bio-Rad & STAR117D800GA \\
\hline Acetyl-Histone H3 (Lys27) & Cell Signaling & $8173 S$ \\
\hline \multicolumn{3}{|c|}{ Chemicals, Peptides, and Recombinant Proteins } \\
\hline SCF & Peprotech & $300-07$ \\
\hline FLT3L & Peprotech & $300-19$ \\
\hline TPO & Peprotech & $300-18$ \\
\hline EPO & Amgen & \\
\hline IL-3 & Peprotech & $200-03$ \\
\hline SFEM II & $\begin{array}{l}\text { Stem Cell } \\
\text { Technologies }\end{array}$ & 09655 \\
\hline Dexamethasone & Sigma & D2915 \\
\hline Doxycycline & Sigma & D9891 \\
\hline Recombinant human insulin & Sigma & 12643 \\
\hline Holo-transferrin & Sigma & T4132 \\
\hline Heparin & Sigma & H3393 \\
\hline Human $\mathrm{AB}$ serum & Sigma & H6914 \\
\hline Cas9 Protein & IDT & 1081058 \\
\hline Concanavalin A & $\begin{array}{l}\text { Bangs } \\
\text { Laboratories, } \\
\text { Inc. }\end{array}$ & BP531 \\
\hline pA-MNase & $\begin{array}{l}\text { Gift from } \\
\text { Steven } \\
\text { Henikoff }\end{array}$ & \\
\hline Dynabeads protein $\mathrm{A}$ & $\begin{array}{l}\text { Thermo Fisher } \\
\text { Scientific }\end{array}$ & 1002D \\
\hline $\begin{array}{l}\text { Dynabeads MyOne } \\
\text { Streptavidin T1 }\end{array}$ & $\begin{array}{l}\text { Thermo Fisher } \\
\text { Scientific }\end{array}$ & 65601 \\
\hline Protease Inhibitor Cocktail & GenDEPOT & $50-101-5486$ \\
\hline \multicolumn{3}{|l|}{ Biological Samples } \\
\hline $\begin{array}{l}\text { Human peripheral blood } \\
\text { CD34+ HSPCs }\end{array}$ & $\begin{array}{l}\text { Stem Cell } \\
\text { Technologies }\end{array}$ & 70060.1 \\
\hline \multicolumn{3}{|c|}{ Critical Commercial Assays } \\
\hline Rapid RNA library kit & $\begin{array}{l}\text { Swift } \\
\text { Biosciences }\end{array}$ & R2096 \\
\hline $\begin{array}{l}\text { Nextera XT library } \\
\text { preparation kit }\end{array}$ & Illumina & FC-131-1024 \\
\hline MinElute PCR purification & Qiagen & 28004 \\
\hline
\end{tabular}




\begin{tabular}{|c|c|c|}
\hline \multicolumn{3}{|l|}{ kit } \\
\hline $\begin{array}{l}\text { Accel-NGS 2S Plus DNA } \\
\text { library kit }\end{array}$ & $\begin{array}{l}\text { Swift } \\
\text { Biosciences }\end{array}$ & 21096 \\
\hline $\begin{array}{l}\text { 2S Combinatorial Dual } \\
\text { Indexing Kit }\end{array}$ & $\begin{array}{l}\text { Swift } \\
\text { Biosciences }\end{array}$ & 28096 \\
\hline $\begin{array}{l}\text { Hi-C Next Generation } \\
\text { Sequencing Kit }\end{array}$ & $\begin{array}{l}\text { Arima } \\
\text { Genomics }\end{array}$ & \\
\hline $\begin{array}{l}\text { KAPA library quantification } \\
\text { kit }\end{array}$ & $\begin{array}{l}\text { KAPA } \\
\text { Biosystems }\end{array}$ & KK4844 \\
\hline RNA clean \& concentrator & $\begin{array}{l}\text { Zymo } \\
\text { Research }\end{array}$ & R1013 \\
\hline \multicolumn{3}{|l|}{ Deposited Data } \\
\hline $\begin{array}{l}\text { Raw and processed NGS } \\
\text { sequencing data }\end{array}$ & This paper & GSE160425 \\
\hline \multicolumn{3}{|l|}{ Analyzed Public Data } \\
\hline HUDEP-2 GATA1 Cut\&Run & $\begin{array}{l}\text { GEO: } \\
\text { GSE104676 }\end{array}$ & GSM2805376 \\
\hline HUDEP-2 CTCF ChIP-seq & $\begin{array}{l}\text { GEO: } \\
\text { GSE104676 }\end{array}$ & GSM3671075 \\
\hline $\begin{array}{l}\text { HUDEP-2 BCL11A ChIP- } \\
\text { seq }\end{array}$ & $\begin{array}{l}\text { GEO: } \\
\text { GSE103445 }\end{array}$ & GSM2771529 \\
\hline $\begin{array}{l}\text { Hematopoietic cells } \\
\text { differentiation ATAC-seq }\end{array}$ & $\begin{array}{l}\text { (Corces, et al., } \\
2016)\end{array}$ & \\
\hline \multicolumn{3}{|l|}{ Oligonucleotides } \\
\hline sg3'HS1-3' & Synthego & GAGUCUUGGGAUGGCUGAAG \\
\hline sg3'HS1-5' & Synthego & GUCCAAGGCAGGACAUGUGU \\
\hline sgHS5-5' & Synthego & GGCACCCACCUUCAAUCAAA \\
\hline sgHS5-3' & Synthego & AGUCCUGCCAGAUAUAGGUC \\
\hline sgOR52A1-GATA1-5' & Synthego & AUGUCUUAGUGGAUAACAGA \\
\hline sgOR52A1-GATA1-3' & Synthego & CAUAUGCUCACAGUAGGAGU \\
\hline sgHPFH-enhancer-5' & Synthego & GGGCAUGUAGACUGUGAUGU \\
\hline sgHPFH-enhancer-3': & Synthego & CAUAUGCUCACAGUAGGAGU \\
\hline sgBCL11A-+58 -5': & Synthego & GGACUGGCAGACCUCUCCAU \\
\hline sgBCL11A-+58-3': & Synthego & CUCUUACUUAUGCACACCUG \\
\hline $\begin{array}{l}\text { 3'HS1-deletion-genotyping } \\
\text { forward }\end{array}$ & $\begin{array}{l}\text { Eurofins } \\
\text { Genomics }\end{array}$ & TCCCTGTGTGATTACTTGCTTAC \\
\hline $\begin{array}{l}\text { 3'HS1-deletion-genotyping } \\
\text { reverse }\end{array}$ & $\begin{array}{l}\text { Eurofins } \\
\text { Genomics }\end{array}$ & AGGTCATAACCATTCAGGTAAACT \\
\hline $\begin{array}{l}\text { 3'HS1-inversion-genotyping } \\
\text { forward }\end{array}$ & $\begin{array}{l}\text { Eurofins } \\
\text { Genomics }\end{array}$ & TCCCTGTGTGATTACTTGCTTAC \\
\hline $\begin{array}{l}\text { 3'HS1-inversion-genotyping } \\
\text { reverse }\end{array}$ & $\begin{array}{l}\text { Eurofins } \\
\text { Genomics }\end{array}$ & GATGAACTACTTACCACTAGGGGTC \\
\hline $\begin{array}{l}\text { 3'HS1-WT-genotyping } \\
\text { forward }\end{array}$ & $\begin{array}{l}\text { Eurofins } \\
\text { Genomics }\end{array}$ & TCCCTGTGTGATTACTTGCTTAC \\
\hline $\begin{array}{l}\text { 3'HS1-WT-genotyping } \\
\text { reverse }\end{array}$ & $\begin{array}{l}\text { Eurofins } \\
\text { Genomics }\end{array}$ & CTTCTGACCCCTAGTGGTGTC \\
\hline $\begin{array}{l}\text { HPFH enhancer-deletion- } \\
\text { genotyping forward }\end{array}$ & $\begin{array}{l}\text { Eurofins } \\
\text { Genomics }\end{array}$ & ACAATGGCCATATGCTCACA \\
\hline
\end{tabular}




\begin{tabular}{|c|c|c|}
\hline $\begin{array}{l}\text { HPFH enhancer-deletion- } \\
\text { genotyping reverse }\end{array}$ & $\begin{array}{l}\text { Eurofins } \\
\text { Genomics }\end{array}$ & GTCCAGGTGATTTTGCTGGT \\
\hline $\begin{array}{l}\text { BCL11A } 58 \text { enhancer- } \\
\text { deletion forward }\end{array}$ & $\begin{array}{l}\text { Eurofins } \\
\text { Genomics }\end{array}$ & GAACAGAGACCACTACTGGCAAT \\
\hline $\begin{array}{l}\text { BCL11A_58 enhancer- } \\
\text { deletion forward }\end{array}$ & $\begin{array}{l}\text { Eurofins } \\
\text { Genomics }\end{array}$ & CTCAGAAAAATGACAGCACCA \\
\hline HBB-qPCR forward & $\begin{array}{l}\text { Eurofins } \\
\text { Genomics }\end{array}$ & CTGAGGAGAAGTCTGCCGTTA \\
\hline HBB-qPCR reverse & $\begin{array}{l}\text { Eurofins } \\
\text { Genomics }\end{array}$ & AGCATCAGGAGTGGACAGAT \\
\hline HBD-qPCR forward & $\begin{array}{l}\text { Eurofins } \\
\text { Genomics }\end{array}$ & GAGGAGAAGACTGCTGTCAATG \\
\hline HBD-qPCR reverse & $\begin{array}{l}\text { Eurofins } \\
\text { Genomics }\end{array}$ & AGGGTAGACCACCAGTAATCTG \\
\hline HBE-qPCR forward & $\begin{array}{l}\text { Eurofins } \\
\text { Genomics }\end{array}$ & GCAAGAAGGTGCTGACTTC \\
\hline HBE-qPCR reverse & $\begin{array}{l}\text { Eurofins } \\
\text { Genomics }\end{array}$ & ACCATCACGTTACCCAGGAG \\
\hline HBG1/2-qPCR forward & $\begin{array}{l}\text { Eurofins } \\
\text { Genomics }\end{array}$ & TGGATGATCTCAAGGGCAC \\
\hline HBG1/2-qPCR reverse & $\begin{array}{l}\text { Eurofins } \\
\text { Genomics }\end{array}$ & TCAGTGGTATCTGGAGGACA \\
\hline ActB-qPCR forward & $\begin{array}{l}\text { Eurofins } \\
\text { Genomics }\end{array}$ & CCTGGCACCCAGCACAATGAAG \\
\hline ActB-qPCR reverse & $\begin{array}{l}\text { Eurofins } \\
\text { Genomics }\end{array}$ & AAGTCATAGTCCGCCTAGAAGC \\
\hline BCL11A-qPCR forward & $\begin{array}{l}\text { Eurofins } \\
\text { Genomics }\end{array}$ & AACCCCAGCACTTAAGCAAA \\
\hline BCL11A-qPCR reverse & $\begin{array}{l}\text { Eurofins } \\
\text { Genomics }\end{array}$ & GGAGGTCATGATCCCCTTCT \\
\hline 3'HS1 HDR template & Gene Universal & $\begin{array}{l}\text { AGACATAGAGAAAGTATATTGTGTTTAAAAGACAG } \\
\text { CTTCTTTATAATTCTATAGAACTAAAACATTCCTAT } \\
\text { TTGCCAAGGCAGTGGAGTTTTTGCTGTTCTTAGAA } \\
\text { CATAATTACTGAAAGACACGCACACATGTCCTGC } \\
\text { CTTGGACAAAAAATTGTATGTCCATCCTTTAAAGG } \\
\text { TCATTCCTTTAATGGTCTTTTCTGGACCTGACCCC } \\
\text { TAGTGGTAAGTAGTTCATCAAACTTTCTTCCCTCC } \\
\text { CTACTTCAGTGATGCATAAGGCAGATCTGCTTTAG } \\
\text { TGTAAGCGAGGTCAGGCCCTCAAGAGTCTTGGGA } \\
\text { TGGCTGAAGATGTAAGAACATTCTATAAGACTTGT } \\
\text { CCAAAGAACTGACTGTTTAATGATTCTGAATATGC } \\
\text { TAGTTCAGAGAGAATCTATTTACCACAAACCTGAA } \\
\text { G }\end{array}$ \\
\hline \multicolumn{3}{|l|}{ Software and Algorithms } \\
\hline HiC-Pro & $\begin{array}{l}\text { (Servant et al., } \\
\text { 2015) }\end{array}$ & https://github.com/nservant/HiC-Pro \\
\hline Juicer & $\begin{array}{l}\text { (Durand et } \\
\text { al.,2016b) }\end{array}$ & https://github.com/theaidenlab/juicer/wiki \\
\hline
\end{tabular}




\begin{tabular}{|c|c|c|}
\hline Juicebox & $\begin{array}{l}\text { (Durand et } \\
\text { al.,2016a; } \\
\text { Durand et al. } \\
2016 b \text { ) }\end{array}$ & http://aidenlab.org/juicebox/ \\
\hline STAR & $\begin{array}{l}\text { (Dobin et al., } \\
\text { 2013) }\end{array}$ & https://github.com/alexdobin/STAR \\
\hline edgeR & $\begin{array}{l}\text { (Robinson et } \\
\text { al., 2010) }\end{array}$ & https://bioconductor.org/packages/edgeR/ \\
\hline Bowtie2 & $\begin{array}{l}\text { (Langmead and } \\
\text { Salzberg, } \\
\text { 2012) }\end{array}$ & http://bowtie-bio.sourceforge.net/bowtie2/index.shtml \\
\hline BWA-MEM & (Li et al., 2013) & http://bio-bwa.sourceforge.net/ \\
\hline SAMtools & $\begin{array}{l}\text { (Li and } \\
\text { Handsaker et } \\
\text { al., 2009) }\end{array}$ & http://samtools.sourceforge.net/ \\
\hline Picard Tools & & http://broadinstitute.github.io/picard/ \\
\hline deepTools & $\begin{array}{l}\text { (Ramirez et al., } \\
\text { 2014) }\end{array}$ & https://deeptools.readthedocs.io/en/develop/ \\
\hline Trim Galore & & $\begin{array}{l}\text { http://www.bioinformatics.babraham.ac.uk/projects/tri } \\
\text { m galore/ }\end{array}$ \\
\hline Trimmomatic & $\begin{array}{l}\text { (Bolger et al., } \\
\text { 2014) }\end{array}$ & http://www.usadellab.org/cms/?page=trimmomatic \\
\hline
\end{tabular}

\section{HUDEP cell culture}

HUDEP clone 2 (HUDEP-2) cells were cultured as previously described (Kurita et al., 2013). Cells were expanded in StemSpan serum-free expansion medium supplemented with $1 \mu \mathrm{M}$ dexamethasone (D2915, Sigma), $1 \mu \mathrm{g} / \mathrm{mL}$ doxycycline (D9891, Sigma), $50 \mathrm{ng} / \mathrm{mL}$ human SCF, 3 units $/ \mathrm{mL}$ EPO, and $1 \%$ penicillin/streptomycin. HUDEP-2 cells were differentiated in a twophase differentiation protocol consisting of IMDM supplemented with $5 \%$ human $A B$ serum, $10 \mu \mathrm{g} / \mathrm{mL}$ recombinant human insulin, $330 \mu \mathrm{g} / \mathrm{mL}$ holo-transferrin, 3 units $/ \mathrm{mL} E P O, 1 \mu \mathrm{g} / \mathrm{mL}$ doxycycline, 2 units $/ \mathrm{mL}$ heparin, and $1 \%$ penicillin/streptomycin. $50 \mathrm{ng} / \mathrm{mL}$ human SCF was included in the phase one of the culture (days 1-3) and withdrawn in the phase two of the culture (days 4 and beyond). Samples were collected on day 5 for flow cytometry, RNA extraction, immunoblot, Hi-C, ATAC-seq, and HPLC analyses.

\section{CRISPR/Cas9-mediated deletion and homologous recombination}

Cas9 nuclease (1081058, IDT) were mixed with synthetically modified sgRNAs (synthesized by Synthego) at a $1: 3$ molar ratio in resuspension buffer $\mathrm{T}$ and incubated at $37^{\circ} \mathrm{C}$ for 10 minutes to form ribonucleoprotein complexes (RNPs). For the CTCF inversion clones, homologydirected repair (HDR) approach was used by adding $2 \mu \mathrm{g}$ of dsDNA homology repair template (synthesized by Gene Universal) to the RNP complexes. dsDNA repair templates were designed to have 90-130 bp of homology arms distal and proximal to the PAM sequence.

For CD34+ cells, about $2.5 \times 10^{5}$ cells were harvested 24 hours after thawing, washed in HBSS (Gibco, 14170112), resuspended in RNP complexes, and electroporated at $1600 \mathrm{~V}$ and 3 pulses 
of $10 \mathrm{~ms}$ using the Neon Transfection system (Thermo Fisher Scientific). For HUDEP-2 cells, $2 \times 10^{5}$ were harvested, resuspended in RNP complexes, and electroporated at $1300 \mathrm{~V}$ and 1 pulse of 20 ms using the Neon Transfection system. Twenty-four hours after electroporation, cells were harvested to assay for deletion or inversion. Genomic DNA was extracted using DirectPCR lysis reagent (102-T, Viagen) followed by proteinase $\mathrm{K}$ treatment at $55^{\circ} \mathrm{C}$. PCR was performed using the EconoTaq PLUS $2 \times$ master mix (30033-2, Lucigen) with the following cycling conditions: $95^{\circ} \mathrm{C}$ for 2 minutes; 45 cycles of $95^{\circ} \mathrm{C}$ for $30 \mathrm{~s}, 55^{\circ} \mathrm{C}$ for $30 \mathrm{~s}, 72^{\circ} \mathrm{C}$ for $40 \mathrm{~s}$; $72^{\circ} \mathrm{C}$ for 5 minutes. Amplicons were purified using the Zymoclean Gel DNA recovery kit and Sanger sequenced.

The sequence of guide RNA and other oligo sequence used to generated guideRNA, genotyping deletion and HDR template is listed in key resources table:

\section{CD34+ cell ex vivo culture and differentiation}

G-CSF mobilized human peripheral blood CD34+ HSPCs were purchased from Stemcell Technologies. Cells were thawed on day 0 into StemSpan serum-free expansion medium (09655, Stem Cell Technologies) supplemented with $100 \mathrm{ng} / \mathrm{mL}$ Flt3L (Peprotech), $50 \mathrm{ng} / \mathrm{mL}$ human stem cell factor (SCF; 300-07, Peprotech), $100 \mathrm{ng} / \mathrm{mL}$ TPO (Peprotech), and 1\% penicillin/streptomycin (Gibco). Electroporation of RNP complexes was done on day 1 and 2 of the culture. Differentiation of CD34+ CD38- into erythroid progenitors were done in four phases of erythroid differentiation medium (EDM) consist of Iscove's modified Dulbecco's medium (IMDM; Gibco) supplemented with 5\% human AB serum (H6914, Sigma), $10 \mu \mathrm{g} / \mathrm{mL}$ recombinant human insulin (I2643, Sigma), 2 units/mL heparin (H3393, Sigma), 3 units $/ \mathrm{mL}$ Epogen (EPO, Amgen), $330 \mu \mathrm{g} / \mathrm{mL}$ holo-transferrin (T4132, Sigma), and $1 \%$ penicillin/streptomycin. EDM was further supplemented with $25 \mathrm{ng} / \mathrm{mL}$ human SCF and $1 \mathrm{ng} / \mathrm{mL}$ human IL-3 (Peprotech) in phase one of the culture (day 4-7). IL-3 was withdrawn and human SCF is decreased to $10 \mathrm{ng} / \mathrm{mL}$ in phase two of the culture (day 7-11). Human SCF is further decreased to $2 \mathrm{ng} / \mathrm{mL}$ in phase three of the culture (day 12-16). Human SCF was withdrawn and holo-transferrin is increased to $1 \mathrm{mg} / \mathrm{mL}$ (day 17 and beyond). Cells were collected on day 21 for flow cytometry, RNA extraction, and Giemsa stain.

\section{Flow Cytometry Analysis of fetal hemoglobin protein expression}

Upon differentiation, the expression of fetal hemoglobin was analyzed by intracellular flow cytometry staining. Briefly, 50,000 cells were fixed and permeabilized in CytoFast Fix/Perm buffer set (426803, BioLegend), and incubated with FITC-conjugated anti-Human Fetal hemoglobin antibody (Miltenyl Biotec, clone \# REA533) in the dark at room temperature for 15 minutes. In addition, phenotypic characterization of cells upon differentiation was done by cellsurface antigens staining with PE anti-human CD71 (334105, BioLegend) and APC anti-human CD235a (561775, BD Biosciences) monoclonal antibodies for 30 minutes at $4^{\circ} \mathrm{C}$. For CD34+ cells, FITC anti-human CD233 (130-119-780, Miltenyi Biotec) was also used to assess differentiation. Cells were analyzed using CytoFLEX S flow cytometer and FlowJo cytometry software was used for data visualization.

\section{RNA isolation and quantitative PCR with reverse transcription (RT-qPCR)}


RNA was extracted from 1-2 million cells using TRIzol (Invitrogen) followed by phenolchloroform extraction. Reverse transcription reactions were performed with random hexamers using iScript (Bio-Rad). BCL11A, HBB, HBD, HBG1/2, and HBE mRNAs were quantified by SsoAdvanced Universal SYBR Green Supermix (1725272, Bio-Rad) and run on a CFX96 Touch Real-Time PCR Detection System (Bio-Rad). The sequence of oligos is listed in Supplemental table 1.

\section{Immunoblot}

Protein samples were denatured in 2X Laemmli buffer (161-0737, Bio-Rad) and boiled for 10 minutes. They were resolved on Novex Tris-Glycine gel (Invitrogen) and transferred onto 0.45uM PVDF membrane (Immobilon-FL PVDF) using Invitrogen Mini Blot Module. Immunoblotting was performed with the following antibodies, BCL11A (ab191401, Abcam), beta-actin (20536-1-AP, Proteintech), ß-globin (sc-21757, Santa Cruz Biotechnology), y-globin (sc-21756, Santa Cruz Biotechnology), and ZTB7A (mab3496, R\&D systems). Starbright B700conjugated goat a-rabbit IgG (12004161, Bio-Rad) and DyLight 800 goat a-mouse $\operatorname{lgG}$ (STAR117D800GA, Bio-Rad) secondary antibodies were purchased from Bio-Rad. Signals were visualized on ChemiDoc MP imaging system (Bio-Rad).

\section{Hemoglobin HPLC}

One million HUDEP-2 cells were harvested and washed with PBS 2 times. After the harvest of the cells. Cells are snap frozen at -80 degrees. Frozen cell pellets are collected for HPLC at the University of Michigan Hospital.

\section{RNA-sequencing}

Total RNA from HUDEP-2 cells upon 5 days of differentiation were isolated using TRIzol followed by phenol-chloroform extraction. Sequencing libraries were prepared from $500 \mathrm{ng}$ of total RNA using Swift Biosciences rapid RNA library kit following the manufacturer's protocol. Libraries were sequenced in the Illumina HiSeq 4000 platform to generate paired-end reads of 2X150 bp.

Paired-end reads were trimmed with trim galore and aligned to hg19 genome with STAR (v2.7.0f) using the default parameters with the following modifications:1) sjdbOverhang was set to sequence length - 1 as recommended in the STAR manual, 2) twopassMode was set to Basic, 3) outReadsUnmapped was set to None, 4) outSAMtype was set to BAM SortedByCoordinate, and 5) quantMode was set to GeneCounts. Gene expression was quantified using STAR's built-in and counts were imported into $R$ (v4.0) using readDGE function to produce DGE list object (Dobin et al., 2013; Robinson et al., 2010).

Differential expression (DE) analysis was performed in $R$ with the edgeR package (v3.30.3). A paired DE analysis was performed to assess changes between groups (3'HS1 deletion or inversion versus WT). Normalization factors and effective library size were applied. Dispersion was estimated using the "estimateDisp" function, with the design matrix as: replicate+group, where "replicate" refers to biological replicates of each sample and "group" refers to the individual clones of deletion or inversion of 3'HS1 and WT. Likelihood ratio test was performed for differential expression with the "glmFit" and "glmLRT" functions. The list of DE genes was further filtered by setting $p$-value $<0.01$ and absolute value of log2 fold-change $>1$. 


\section{ATAC-sequencing}

ATAC-seq was performed with Illumina Nextera XT library preparation kit (FC-131-1024, Illumina) as previously described (Buenrostro et al., 2015). Upon 5 days of HUDEP-2 differentiation, 50,000 cells were harvested and permeabilized in $50 \mathrm{uL}$ of cold lysis buffer (10 $\mathrm{mM}$ Tris- $\mathrm{HCl}, \mathrm{pH} 7.4,10 \mathrm{mM} \mathrm{NaCl}, 3 \mathrm{mM} \mathrm{MgCl}$, 0.1\% IGEPAL CA-630). The transposition reaction was carried out at $37^{\circ} \mathrm{C}$ for 30 minutes with agitation in $50 \mathrm{uL}$ volume containing $25 \mathrm{uL}$ of 2X TD buffer and 2.5uL of Nextera Tn5 transposase. DNA was purified with Qiagen MinElute PCR purification kit. Library amplification was done with KAPA HiFi HotStart ReadyMix PCR kit, and the resulting libraries were purified with Qiagen MinElute PCR Purification Kit. Libraries were sequenced in the Illumina HiSeq 4000 platform to generate paired-end reads of 2 X150 bp.

Paired-end reads were trimmed using Trim Galore (version 0.6.1) and aligned to hg19 using Burrows-Wheeler Aligner (bwa-mem, version 0.7.17). The resulting alignments were sorted, indexed using SAMtools (version 1.9), and marked for duplicates with samblaster (version 0.1.24). Reads were then normalized using deeptools bamCoverage with RPGC parameter and visualized with IGV.

\section{CUT\&RUN}

CTCF Cut\&Run was performed according to published protocol (Meers et al., 2019). Briefly, upon 5 days of differentiation, 500,000 HUDEP2 cells were immobilized with BioMag Plus Concanavalin A (BangsLabs, Inc). Cells were permeabilized and incubated with CTCF antibody (ab70303, Abcam) overnight. After washing away unbound antibody, pA-MNase (a gift from Dr. Steven Henikoff) was then added to the cells and incubated for $5 \mathrm{~min}$ in a metal block on ice. The MNase reaction was stopped, chromatin was released by diffusion at $37 \mathrm{C}$ for 30 minutes, and DNA was extracted. Swift Biosciences Accel-NGS 2S Plus DNA library kit was used to construct NGS libraries. Libraries were sequenced on the Illumina HiSeq 4000 platform to generate paired-end reads of 2X150 bp.

Paired-end sequencing reads were trimmed using Trimmomatic (version 0.36) and aligned to hg19 genome assembly using Bowtie2 (version 2.3.5) with the parameter "--dovetail --phred33". The resulting alignments were indexed, sorted, and marked for duplicates with Picard "MarkDuplicates" function. Reads were then normalized using deeptools bamCoverage with RPGC parameter and visualized with IGV.

\section{Chromatin Immunoprecipitation}

About 2 million HUDEP-2 cells upon 5 days of differentiation were harvested and fixed with 1\% formaldehyde for 10 minutes at room temperature. Fixation was quenched with $0.125 \mathrm{M}$ glycine. Cells were washed twice with ice-cold PBS, lysed in $0.13 \mathrm{~mL}$ of lysis buffer $(10 \mathrm{mM}$ Tris $\mathrm{pH} 8.0$, $0.25 \%$ SDS, $2 \mathrm{mM}$ EDTA, 1X protease inhibitors) and sonicated in a Covaris microtube with Covaris ultrasonicator (E220, Covaris). Sonicated chromatin was diluted with $0.2 \mathrm{~mL}$ of equilibration buffer (10 mM Tris $\mathrm{pH} 8.0,233 \mathrm{mM} \mathrm{NaCl}, 1.66 \%$ Triton X-100, 0.166\% sodium deoxycholate, $1 \mathrm{mM}$ EDTA, $1 \mathrm{X}$ protease inhibitors) and spun down to pellet insoluble materials. Supernatant was mixed with $2 \mu \mathrm{g}$ of antibody (H3K27ac, D5E4, Cell Signaling) and incubated at $4 \mathrm{C}$ overnight. $10 \mu \mathrm{L}$ of Dynabeads protein A (Thermo Fisher Scientific) were washed twice with $0.1 \%$ BSA/PBS and incubated overnight alongside the chromatin. After overnight rotating, 
beads were transferred to the tube containing chromatin and incubated for 2 hours. Beads were washed twice with RIPA-LS (10 mM Tris pH 8.0, $140 \mathrm{mM} \mathrm{NaCl}, 1 \mathrm{mM}$ EDTA, 0.1\% SDS, 0.1\% sodium deoxycholate, $1 \%$ Triton X-100), twice with RIPA-HS (10 mM Tris pH 8.0, $500 \mathrm{mM} \mathrm{NaCl}$, $1 \mathrm{mM}$ EDTA, $0.1 \%$ SDS, $0.1 \%$ sodium deoxycholate, $1 \%$ Triton X-100), twice with RIPA-LiCl (10 $\mathrm{mM}$ Tris $\mathrm{pH} 8.0,250 \mathrm{mM} \mathrm{LiCl}, 1 \mathrm{mM}$ EDTA, 0.5\% NP-40, 0.5\% sodium deoxycholate), and once with $10 \mathrm{mM}$ Tris $\mathrm{pH}$ 8.0. After washing, $48 \mathrm{uL}$ of elution buffer (10 mM Tris pH 8.0, $5 \mathrm{mM}$ EDTA, $300 \mathrm{mM} \mathrm{NaCl}, 0.4 \% \mathrm{SDS}$ ) with $2 \mathrm{uL}$ of $20 \mathrm{mg} / \mathrm{mL}$ of proteinase $\mathrm{K}$ (Viagen) were added to the beads and incubated for 1 hour at $55^{\circ} \mathrm{C}$ followed by overnight incubation at $65^{\circ} \mathrm{C}$ to decrosslink. Beads were magnetized and supernatant was purified with phenol-chloroform. DNA was precipitated with ice-cold absolute ethanol, washed with $75 \%$ ethanol, and eluted with $20 \mathrm{uL}$ of $10 \mathrm{mM}$ of Tris pH 8.0. Accel-NGS 2S Plus DNA library kit (21096, Swift Bioscience) was used to construct the libraries with the 2S combinatorial dual indexing kit (28096, Swift Bioscience). Libraries were sequenced on the HiSeq 4000 platform to generate paired-end reads sequencing 2X150 bp.

Reads were aligned to the human genome (hg19) using Bowtie2 (version 2.3.5). The resulting alignments bam files were indexed, sorted with SAMtools and marked for duplicates with Picard "MarkDuplicates" function. Reads were then normalized using deeptools bamCoverage with RPGC parameter and visualized with IGV.

\section{Chromatin Conformation Capture (HiC and capture $\mathrm{HiC}$ ) Hi-C Library preparation}

Approximately 2 million cells of each HUDEP-2 clone were differentiated for 5 days and fixed in $1 \%$ formaldehyde. Hi-C libraries were generated using the Arima-HiC kit, according to the manufacturer's protocols. Libraries were prepared using the Accel-NGS 2S Plus kit (Swift Biosciences, 21096), with single indexing kit 2S Set A (Swift Biosciences, 26148). The final amplification cycle numbers for each library were determined by qPCR in the QC2 step of the Arima protocol. Quantification of the libraries was performed with KAPA Library Quantification Kit (Roche, KK4824). The libraries were then pooled for sequencing on NovaSeq S4 to get between 300 and 400 million reads each.

\section{Probe Design}

The capture probes were designed as previously described (Sanborn et al., 2015). 3822 oligos of probe sequence covering Chr11:4665299 to 5954156 with adaptor sequence on both end as following: ATCGCACCAGCGTGT N120 CACTGCGGCTCCTCA was synthesized by GeneScripts. The biotinylated RNA probes specific to the $\beta$-globin locus were made as described. Briefly, the desired sequences were amplified out of the pool with primer sequences complementary to both ends using KAPA HiFi HotStart MasterMix for 12 cycles. The oligonucleotides were then prepared for in vitro transcription by adding a T7 promoter to the forward primer and amplifying for a further 15 cycles. In vitro transcription with Biotin-16-UTP was performed with NEB HiScribe T7 for 2 hours at $37^{\circ} \mathrm{C}$. The template DNA was degraded by adding $1 \mathrm{uL}$ DNase and incubating at $37^{\circ} \mathrm{C}$ for a further 15 minutes, and then stopping the reaction by adding $1 \mathrm{uL} 0.5 \mathrm{M}$ EDTA. The RNA was then purified using Zymo RNA Clean \& Concentrator columns, eluting in $15 \mathrm{uL}$ elution buffer. We then added $1 \mathrm{U} / \mathrm{uL}$ RNase Inhibitor (NEB, M0314), aliquoted and stored at $-80^{\circ} \mathrm{C}$ until needed for the capture.

\section{Capture}


150-500 ng of the previously created Hi-C libraries were diluted to $25 \mathrm{uL}$ and mixed with $2.5 \mathrm{ug}$ Cot-1 DNA and $10 \mathrm{ug}$ salmon sperm DNA and heated to $95^{\circ} \mathrm{C}$ for 5 minutes, then held at $65^{\circ} \mathrm{C}$ for at least 5 minutes. $33 \mathrm{uL}$ of prewarmed (to $65^{\circ} \mathrm{C}$ ) hybridization buffer (10X SSPE, 10X Denhardt's buffer, $10 \mathrm{mM}$ EDTA, and $0.2 \%$ SDS), along with 6 uL of RNA probe mixture (500 ng biotinylated-RNA probes and $20 \mathrm{U}$ RNase inhibitor) were added to the DNA mixture and hybridized for $24 \mathrm{hr}$ at $65^{\circ} \mathrm{C}$. After the hybridization incubation was complete, $50 \mathrm{uL}$ of Streptavidan T1 beads (Dynabeads, Life Technologies) were washed in Bind-and-Wash buffer $(1 \mathrm{M} \mathrm{NaCl}, 10 \mathrm{mM}$ Tris- $\mathrm{HCl}, \mathrm{pH} 7.5$, and $1 \mathrm{mM}$ EDTA), resuspended in $134 \mathrm{uL}$ of the same buffer, and then added to the hybridization mixture. The beads were allowed to bind to the biotinylated, hybridized DNA and RNA mixture for 30 minutes at room temperature before separating and discarding the supernatant. The bead-bound DNA was then washed once with low-stringency wash buffer (1X SSC, $0.1 \%$ SDS), for 15 minutes at room temperature, and three times with high-stringency wash $(0.1 \mathrm{XSC}, 0.1 \% \mathrm{SDS})$ for 10 minutes at $65^{\circ} \mathrm{C}$, separating the beads on a magnet each time before discarding the supernatant. After the last wash, the beads were resuspended in $21 \mathrm{uL}$ nuclease-free water. $1 \mathrm{uL}$ was diluted 1:1000 and had qPCR performed as for QC2 of the Arima protocol to determine the number of cycles to amplify the enriched libraries.

\section{Virtual 4C}

Virtual $4 \mathrm{C}$ track is generated by using juicebox. Horizonal and vertical $1 \mathrm{D}$ track of the $5 \mathrm{~kb}$ (chr11:5,165,001-5,170,000) X 5kb (chr11:5,275,001-5,280,000) pixel is generated with juicebox "generate 1D track" function.

\section{Acknowledgements}

We would like to thank Dr. James Engel for valuable discussions and technical expertise on the HUDEP-2 cell culture and differentiation. XZ was supported by the VARI fellowship. XZ is supported by the ASH scholar award and is an EvansMDS Young Investigator.

\section{References}

Bank, A. (2006). Regulation of human fetal hemoglobin: new players, new complexities. Blood 107, 435443.

Bauer, D.E., Kamran, S.C., Lessard, S., Xu, J., Fujiwara, Y., Lin, C., Shao, Z., Canver, M.C., Smith, E.C., Pinello, L., et al. (2013). An erythroid enhancer of BCL11A subject to genetic variation determines fetal hemoglobin level. Science 342, 253-257.

Bauer, D.E., Kamran, S.C., and Orkin, S.H. (2012). Reawakening fetal hemoglobin: prospects for new therapies for the beta-globin disorders. Blood 120, 2945-2953.

Bender, M.A., Byron, R., Ragoczy, T., Telling, A., Bulger, M., and Groudine, M. (2006). Flanking HS-62.5 and 3 ' HS1, and regions upstream of the LCR, are not required for beta-globin transcription. Blood 108, 1395-1401.

Breda, L., Motta, I., Lourenco, S., Gemmo, C., Deng, W., Rupon, J.W., Abdulmalik, O.Y., Manwani, D., Blobel, G.A., and Rivella, S. (2016). Forced chromatin looping raises fetal hemoglobin in adult sickle cells to higher levels than pharmacologic inducers. Blood 128, 1139-1143.

Buenrostro, J.D., Wu, B., Chang, H.Y., and Greenleaf, W.J. (2015). ATAC-seq: A Method for Assaying Chromatin Accessibility Genome-Wide. Curr Protoc Mol Biol 109, 2129 21-21 2929.

Bulger, M., Schubeler, D., Bender, M.A., Hamilton, J., Farrell, C.M., Hardison, R.C., and Groudine, M. (2003). A complex chromatin landscape revealed by patterns of nuclease sensitivity and histone modification within the mouse beta-globin locus. Mol Cell Biol 23, 5234-5244. 
Corces, M.R., Buenrostro, J.D., Wu, B., Greenside, P.G., Chan, S.M., Koenig, J.L., Snyder, M.P., Pritchard, J.K., Kundaje, A., Greenleaf, W.J., et al. (2016). Lineage-specific and single-cell chromatin accessibility charts human hematopoiesis and leukemia evolution. Nat Genet 48, 1193-1203.

Deng, W., Rupon, J.W., Krivega, I., Breda, L., Motta, I., Jahn, K.S., Reik, A., Gregory, P.D., Rivella, S., Dean, A., et al. (2014). Reactivation of developmentally silenced globin genes by forced chromatin looping. Cell $158,849-860$.

Dobin, A., Davis, C.A., Schlesinger, F., Drenkow, J., Zaleski, C., Jha, S., Batut, P., Chaisson, M., and Gingeras, T.R. (2013). STAR: ultrafast universal RNA-seq aligner. Bioinformatics 29, 15-21.

Feingold, E.A., and Forget, B.G. (1989). The breakpoint of a large deletion causing hereditary persistence of fetal hemoglobin occurs within an erythroid DNA domain remote from the beta-globin gene cluster. Blood 74, 2178-2186.

Forget, B.G. (1998). Molecular basis of hereditary persistence of fetal hemoglobin. Ann N Y Acad Sci 850, 38-44.

Grevet, J.D., Lan, X., Hamagami, N., Edwards, C.R., Sankaranarayanan, L., Ji, X., Bhardwaj, S.K., Face, C.J., Posocco, D.F., Abdulmalik, O., et al. (2018). Domain-focused CRISPR screen identifies HRI as a fetal hemoglobin regulator in human erythroid cells. Science 361, 285-290.

Hassell, K.L. (2010). Population estimates of sickle cell disease in the U.S. Am J Prev Med 38, S512-521. Huang, P., Keller, C.A., Giardine, B., Grevet, J.D., Davies, J.O.J., Hughes, J.R., Kurita, R., Nakamura, Y., Hardison, R.C., and Blobel, G.A. (2017). Comparative analysis of three-dimensional chromosomal architecture identifies a novel fetal hemoglobin regulatory element. Genes Dev 31, 1704-1713. Jessica Zuin, G.R., Yinxiu Zhan, Julie Cramard, Josef Redolfi, Ewa Piskadlo, Pia Mach, Mariya Kryzhanovska, Gergely Tihanyi, Hubertus Kohler, Peter Meister, Sebastien Smallwood, Luca Giorgetti (2021). Nonlinear control of transcription through enhancer-promoter interactions. biorxiv.

Kurita, R., Suda, N., Sudo, K., Miharada, K., Hiroyama, T., Miyoshi, H., Tani, K., and Nakamura, Y. (2013). Establishment of immortalized human erythroid progenitor cell lines able to produce enucleated red blood cells. PLoS One 8, e59890.

Liu, N., Hargreaves, V.V., Zhu, Q., Kurland, J.V., Hong, J., Kim, W., Sher, F., Macias-Trevino, C., Rogers, J.M., Kurita, R., et al. (2018). Direct Promoter Repression by BCL11A Controls the Fetal to Adult Hemoglobin Switch. Cell 173, 430-442 e417.

Martyn, G.E., Wienert, B., Yang, L., Shah, M., Norton, L.J., Burdach, J., Kurita, R., Nakamura, Y., Pearson, R.C.M., Funnell, A.P.W., et al. (2018). Natural regulatory mutations elevate the fetal globin gene via disruption of BCL11A or ZBTB7A binding. Nat Genet 50, 498-503.

Masuda, T., Wang, X., Maeda, M., Canver, M.C., Sher, F., Funnell, A.P., Fisher, C., Suciu, M., Martyn, G.E., Norton, L.J., et al. (2016). Transcription factors LRF and BCL11A independently repress expression of fetal hemoglobin. Science 351, 285-289.

Meers, M.P., Bryson, T.D., Henikoff, J.G., and Henikoff, S. (2019). Improved CUT\&RUN chromatin profiling tools. Elife 8.

Moir-Meyer, G., Cheong, P.L., Olijnik, A.A., Brown, J., Knight, S., King, A., Kurita, R., Nakamura, Y., Gibbons, R.J., Higgs, D.R., et al. (2018). Robust CRISPR/Cas9 Genome Editing of the HUDEP-2 Erythroid Precursor Line Using Plasmids and Single-Stranded Oligonucleotide Donors. Methods Protoc 1. Roayaei Ardakany, A., Gezer, H.T., Lonardi, S., and Ay, F. (2020). Mustache: multi-scale detection of chromatin loops from $\mathrm{Hi}-\mathrm{C}$ and Micro-C maps using scale-space representation. Genome Biol 21, 256. Robinson, M.D., McCarthy, D.J., and Smyth, G.K. (2010). edgeR: a Bioconductor package for differential expression analysis of digital gene expression data. Bioinformatics 26, 139-140.

Sanborn, A.L., Rao, S.S., Huang, S.C., Durand, N.C., Huntley, M.H., Jewett, A.I., Bochkov, I.D., Chinnappan, D., Cutkosky, A., Li, J., et al. (2015). Chromatin extrusion explains key features of loop and domain formation in wild-type and engineered genomes. Proc Natl Acad Sci U S A 112, E6456-6465. 
Sankaran, V.G., Menne, T.F., Xu, J., Akie, T.E., Lettre, G., Van Handel, B., Mikkola, H.K., Hirschhorn, J.N., Cantor, A.B., and Orkin, S.H. (2008). Human fetal hemoglobin expression is regulated by the developmental stage-specific repressor BCL11A. Science 322, 1839-1842.

Sankaran, V.G., Xu, J., Byron, R., Greisman, H.A., Fisher, C., Weatherall, D.J., Sabath, D.E., Groudine, M., Orkin, S.H., Premawardhena, A., et al. (2011). A functional element necessary for fetal hemoglobin silencing. N Engl J Med 365, 807-814.

Sankaran, V.G., Xu, J., Ragoczy, T., Ippolito, G.C., Walkley, C.R., Maika, S.D., Fujiwara, Y., Ito, M., Groudine, M., Bender, M.A., et al. (2009). Developmental and species-divergent globin switching are driven by BCL11A. Nature 460, 1093-1097.

Traxler, E.A., Yao, Y., Wang, Y.D., Woodard, K.J., Kurita, R., Nakamura, Y., Hughes, J.R., Hardison, R.C., Blobel, G.A., Li, C., et al. (2016). A genome-editing strategy to treat beta-hemoglobinopathies that recapitulates a mutation associated with a benign genetic condition. Nat Med 22, 987-990.

Vinjamur, D.S., and Bauer, D.E. (2018). Growing and Genetically Manipulating Human Umbilical Cord Blood-Derived Erythroid Progenitor (HUDEP) Cell Lines. Methods Mol Biol 1698, 275-284.

Xu, J., Peng, C., Sankaran, V.G., Shao, Z., Esrick, E.B., Chong, B.G., Ippolito, G.C., Fujiwara, Y., Ebert, B.L., Tucker, P.W., et al. (2011). Correction of sickle cell disease in adult mice by interference with fetal hemoglobin silencing. Science 334, 993-996.

Ye, L., Wang, J., Tan, Y., Beyer, A.I., Xie, F., Muench, M.O., and Kan, Y.W. (2016). Genome editing using CRISPR-Cas9 to create the HPFH genotype in HSPCs: An approach for treating sickle cell disease and beta-thalassemia. Proc Natl Acad Sci U S A 113, 10661-10665.

Zeng, J., Wu, Y., Ren, C., Bonanno, J., Shen, A.H., Shea, D., Gehrke, J.M., Clement, K., Luk, K., Yao, Q., et al. (2020). Therapeutic base editing of human hematopoietic stem cells. Nat Med 26, 535-541. 


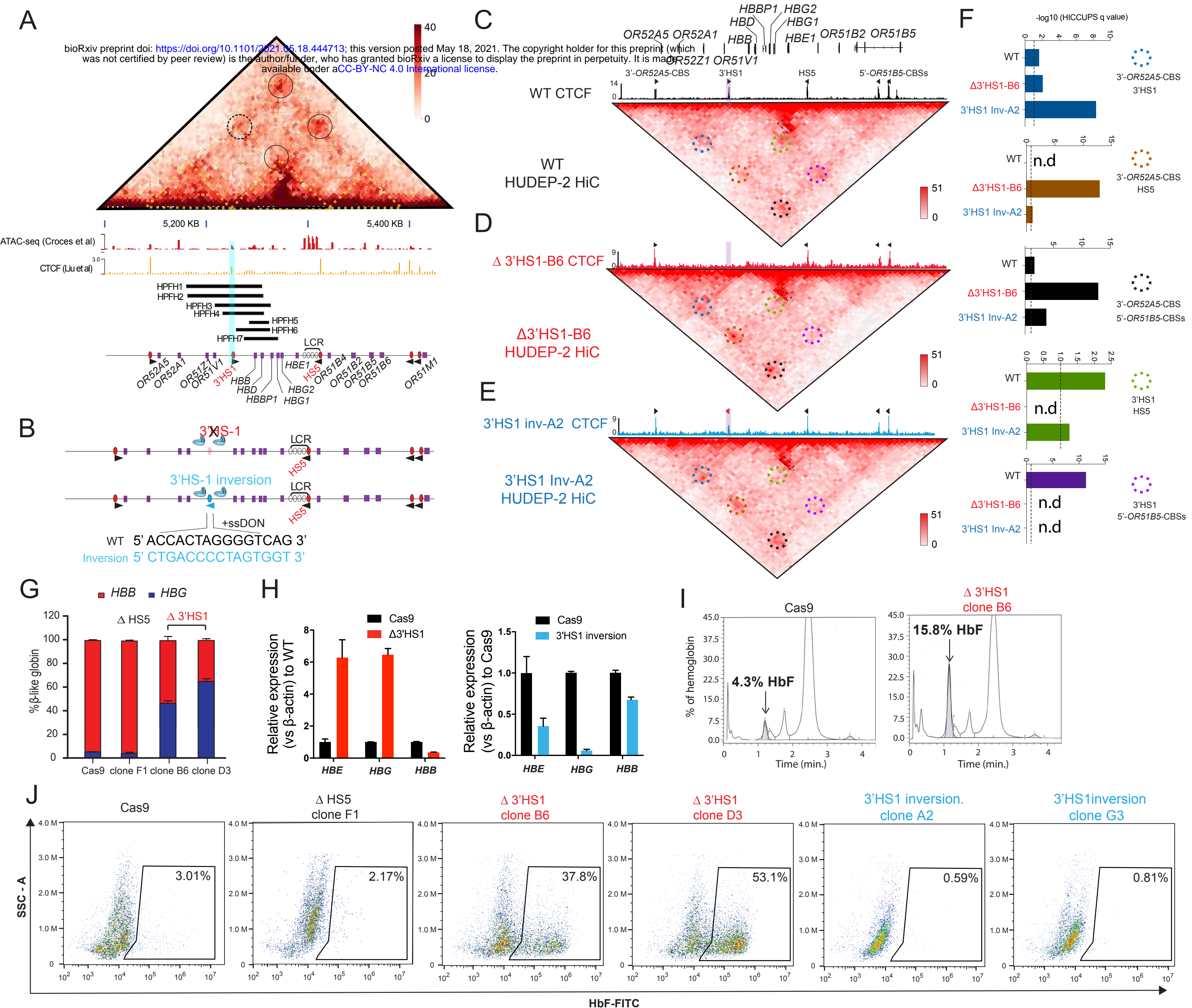


A

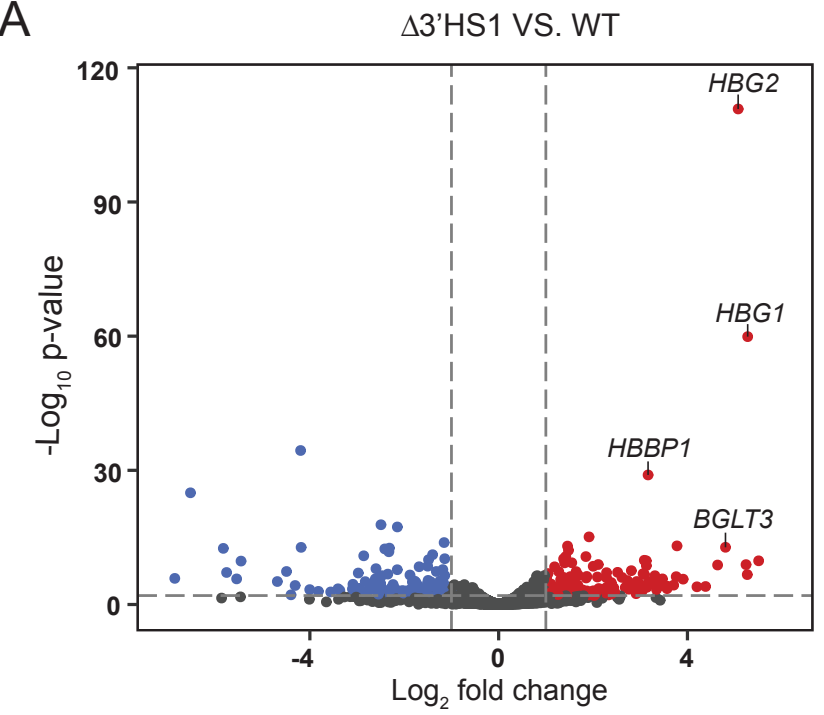

C

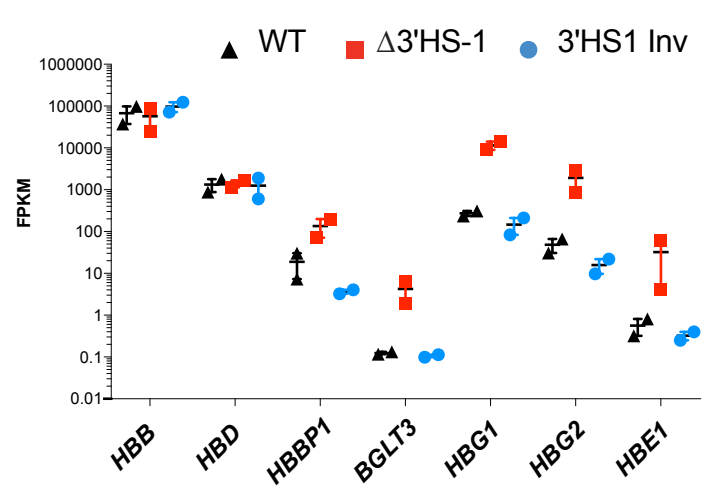

E

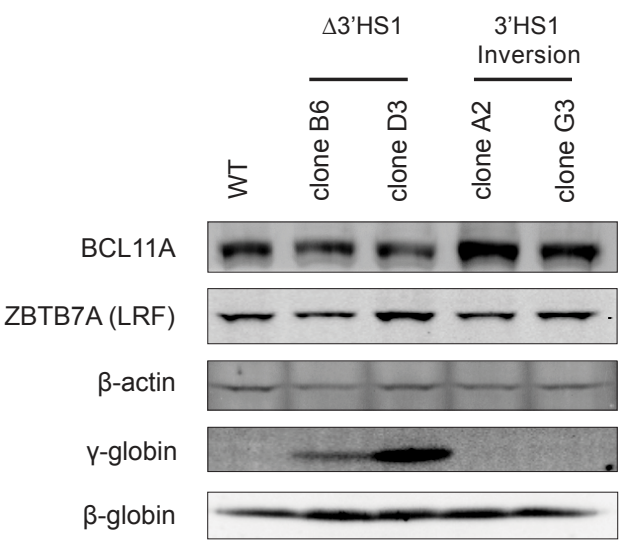

B 3'HS1 INVERSION VS. WT

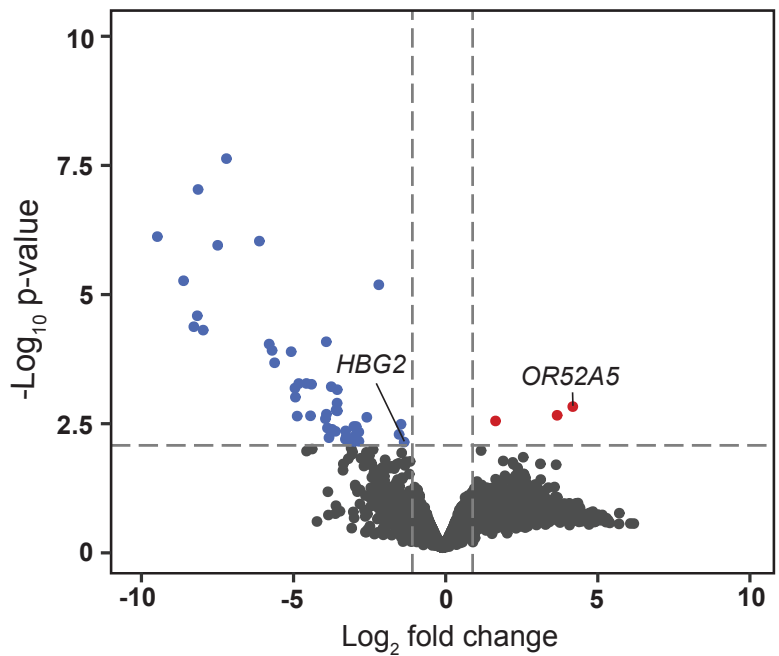

D

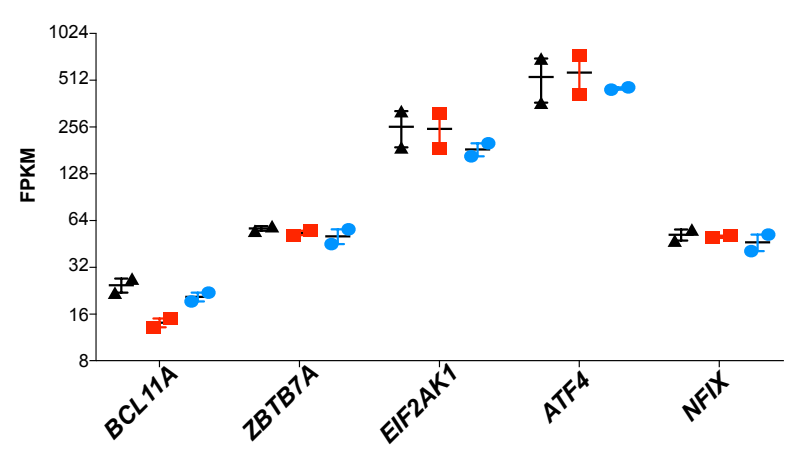

F

$\square$ HBB $\square$ HBE $\square$ HBD $\triangle 3^{\prime} \mathrm{HS} 1$

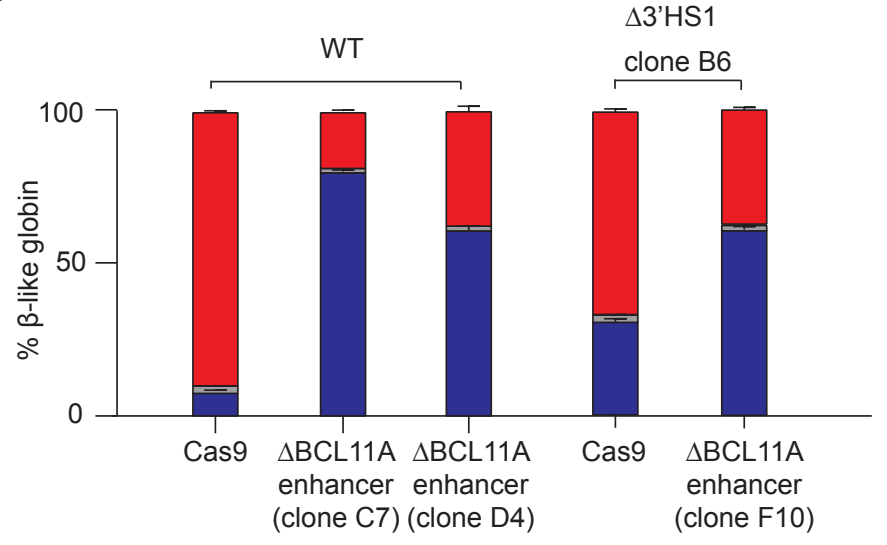


bioRxiv preprint doi: https://doi.org/10.1101/2021.05.18.444713; this version posted May 18, 2021. The copyright holder for this preprint (which

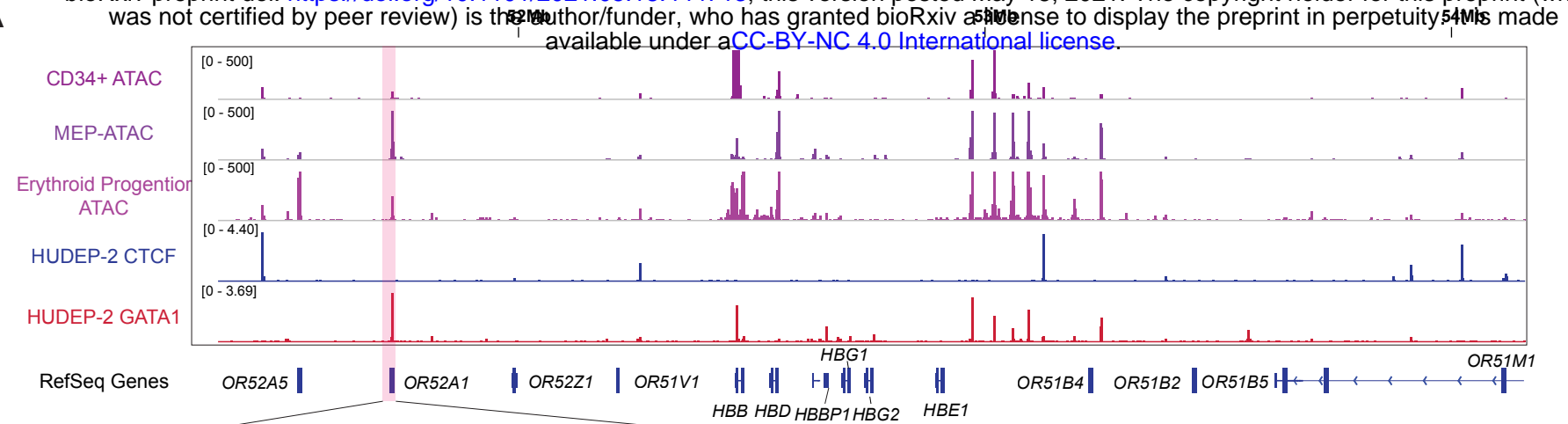

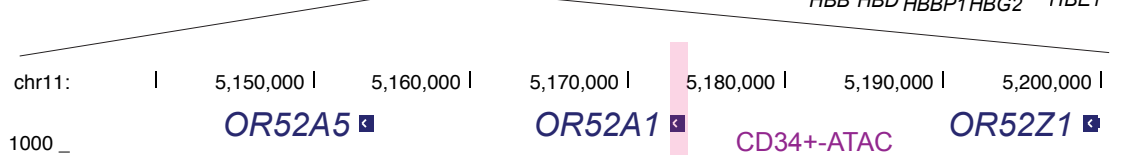
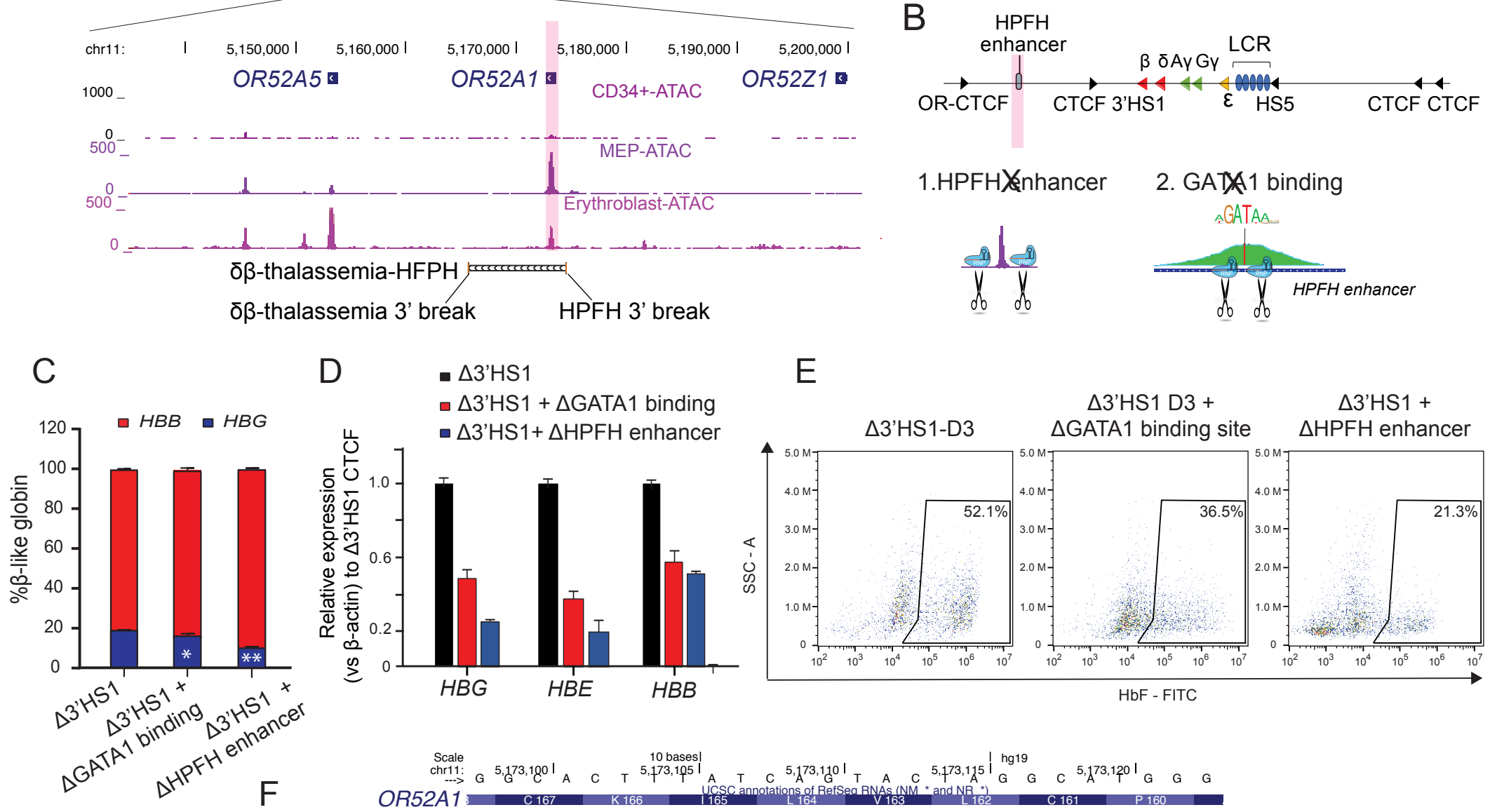

E
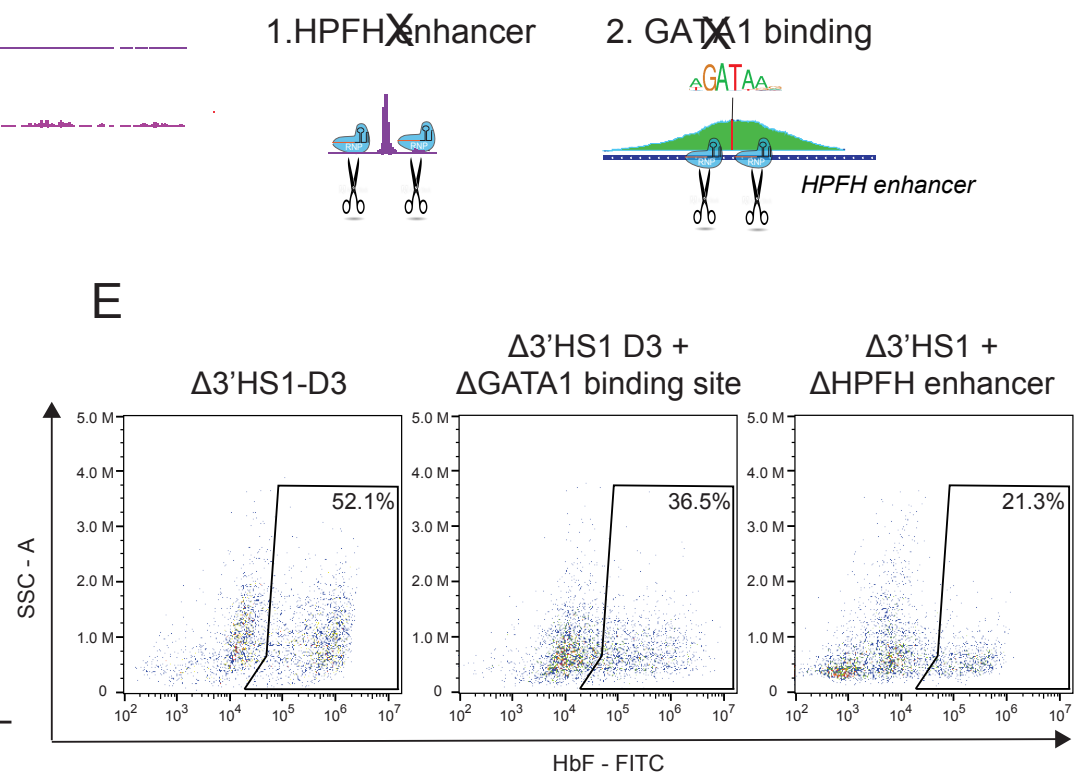
GATA1 binding sites

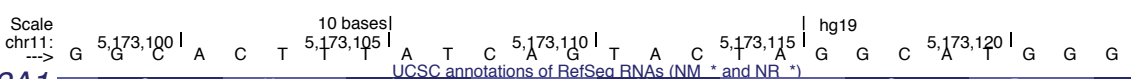

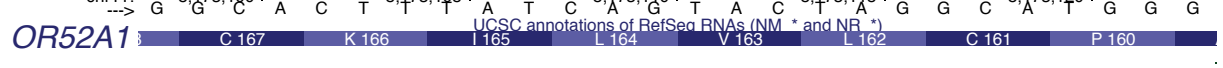
Multiz Alignments of mammals
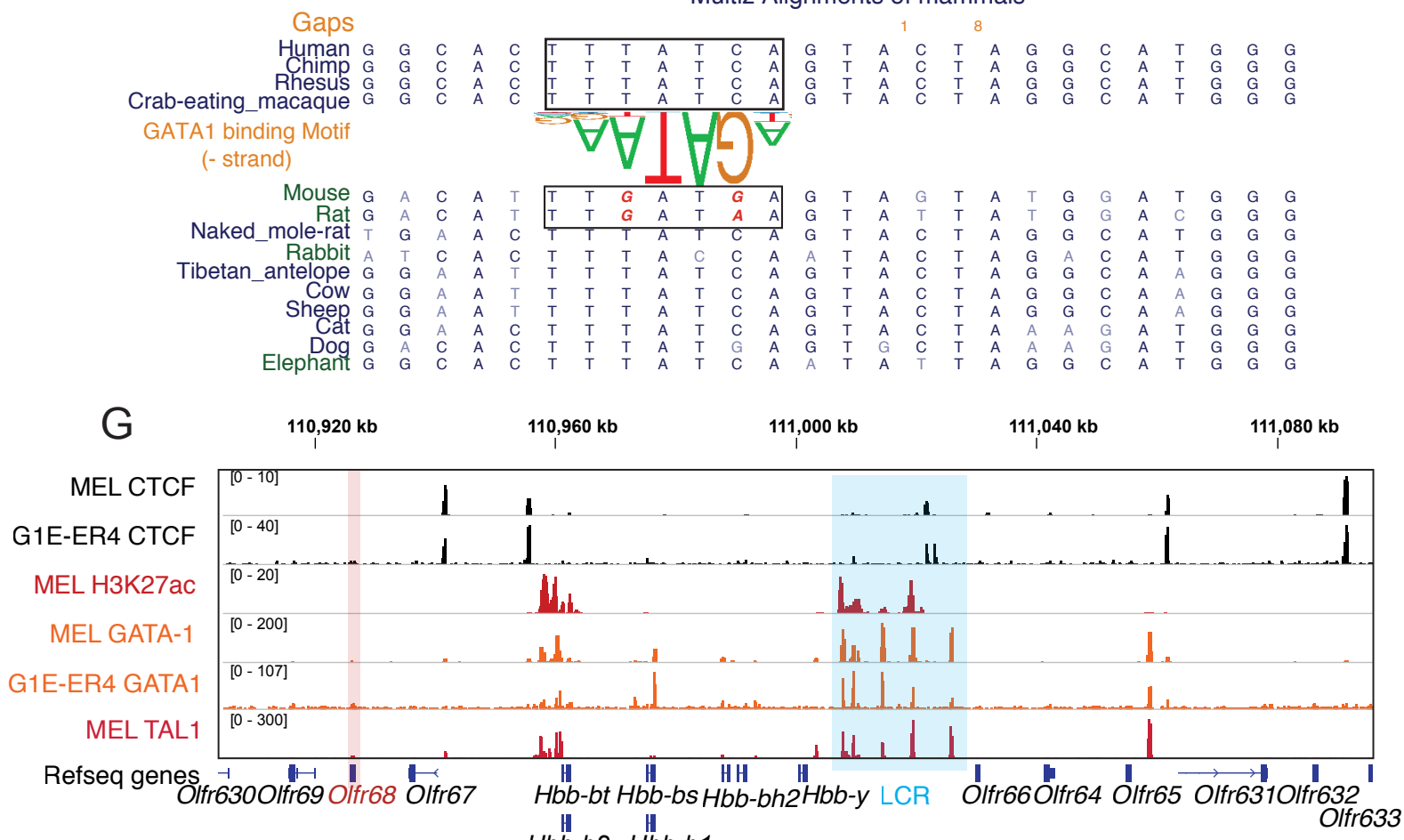
A

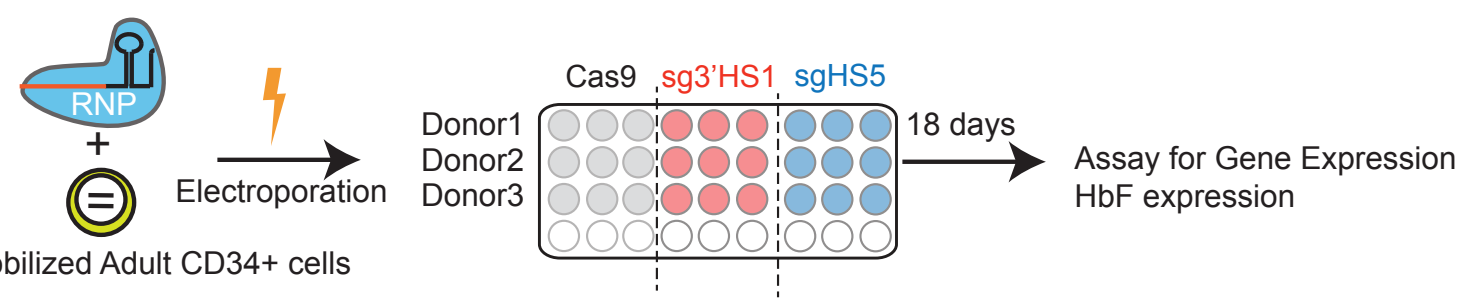

B

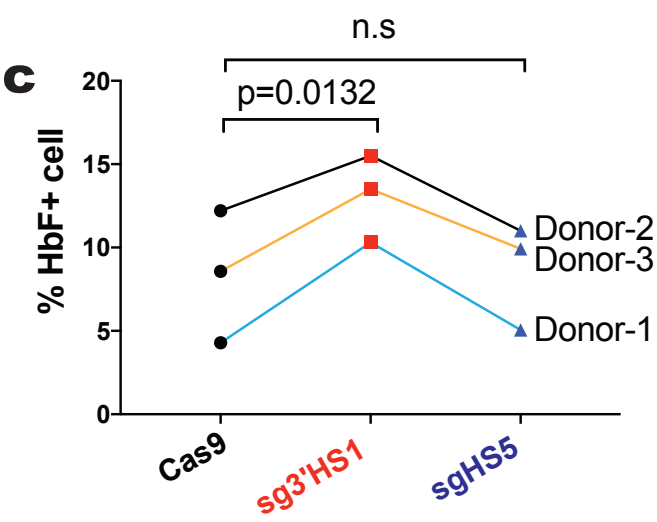

C
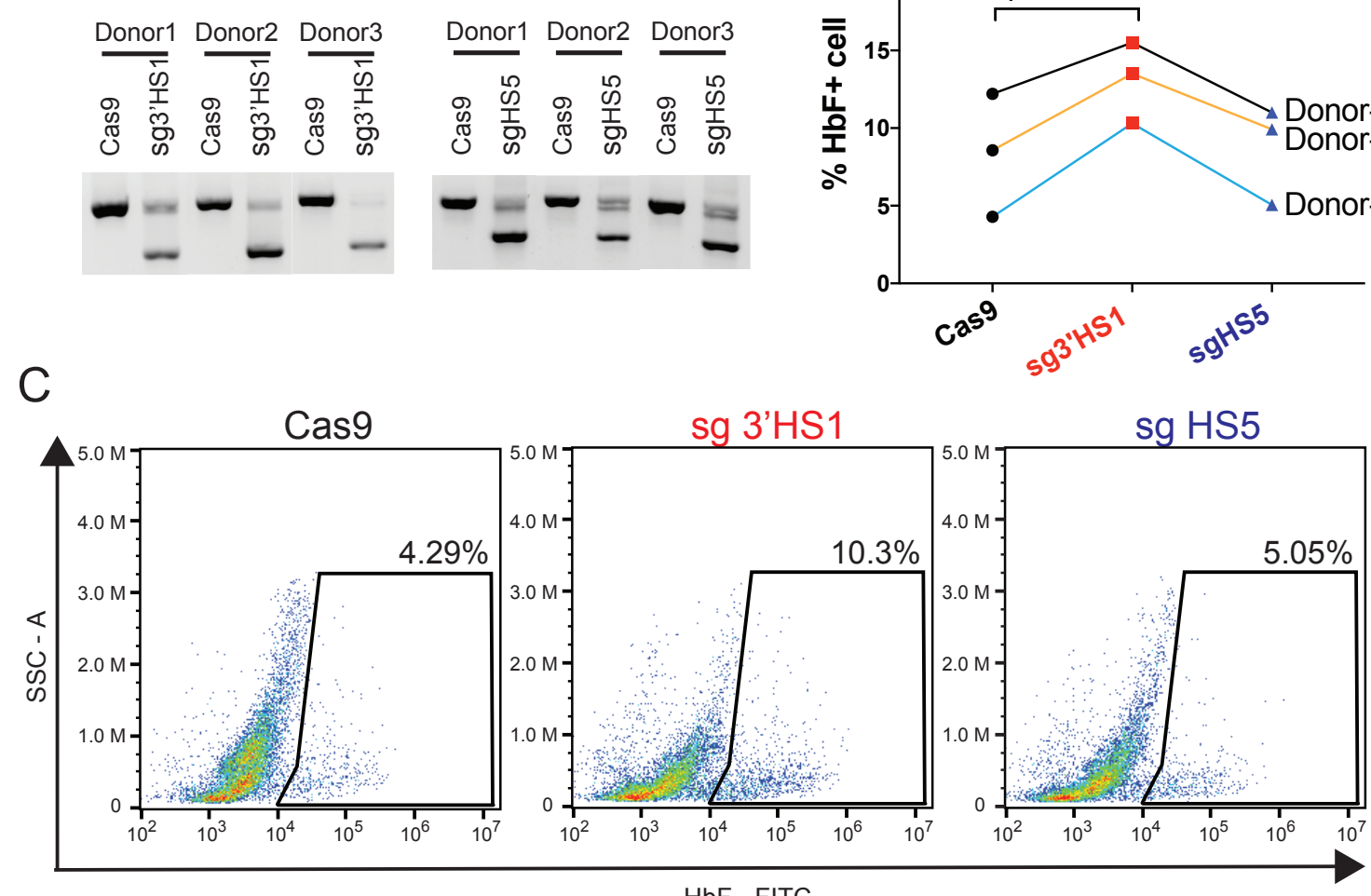

$\mathrm{HbF}$ - FITC

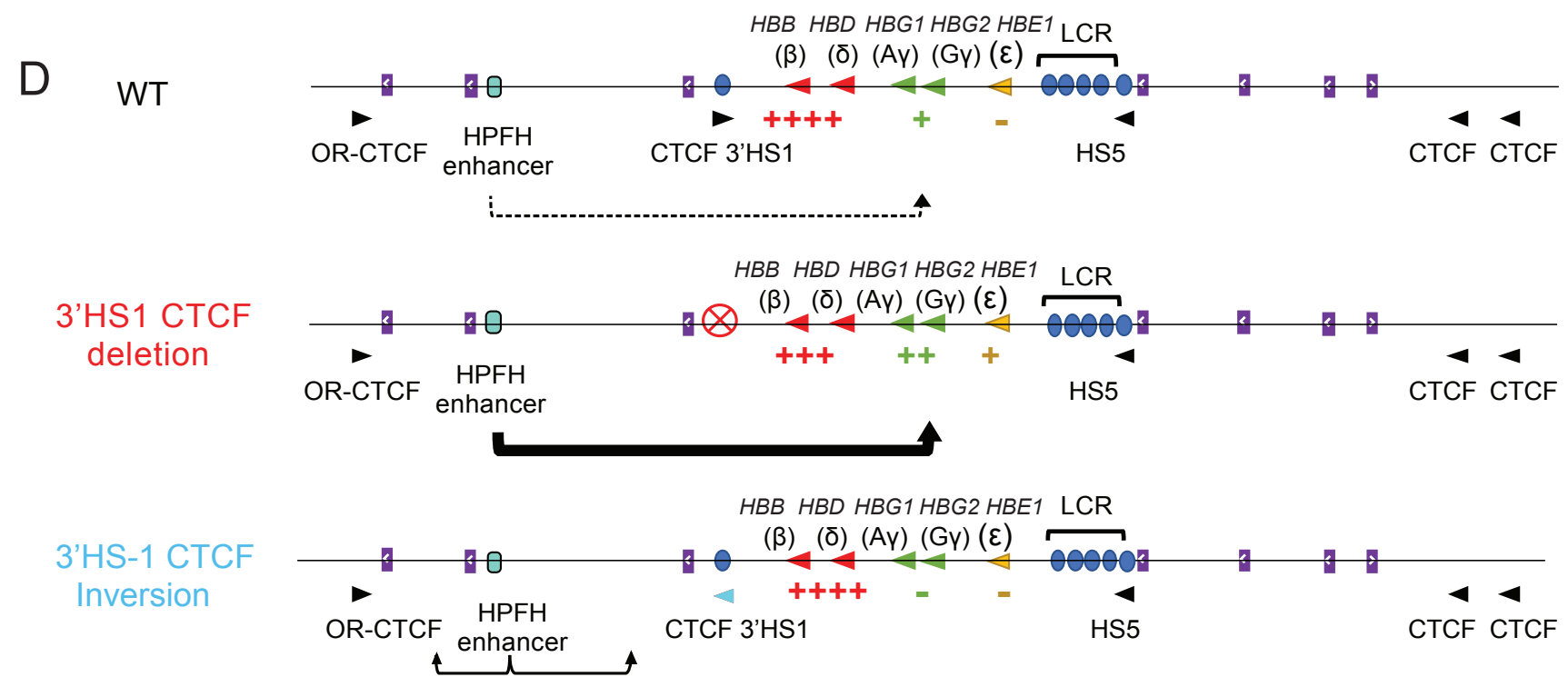

